\title{
Simulating meteorological profiles to study noise propagation from freeways
}

\author{
S.R. Shaffer ${ }^{a, *}$, H.J.S. Fernando ${ }^{b}$, N.C. Ovenden ${ }^{c}$, M. Moustaoui ${ }^{\text {d, }}$, \\ A. Mahalov ${ }^{\mathrm{d}}$ \\ ${ }^{a}$ The School for Engineering of Matter, Transport and Energy (SEMTE), Arizona State \\ University, 501 E. Tyler Mall, Tempe, AZ, 85287-9809. \\ ${ }^{b}$ Department of Civil and Environmental Engineering and Earth Sciences, University of \\ Notre Dame, 156 Fitzpatrick Hall, Notre Dame, IN 46556-5637 \\ ${ }^{c}$ Department of Mathematics, University College London, Gower Street, London, WC1E \\ $6 B T$, United Kingdom \\ ${ }^{d}$ School of Mathematical and Statistical Sciences, Arizona State University, Tempe, AZ
}

85287-1804

\begin{abstract}
Forecasts of noise pollution from a highway line segment noise source are obtained from a sound propagation model utilizing effective sound speed profiles derived from a Numerical Weather Prediction (NWP) limited area forecast with $1 \mathrm{~km}$ horizontal resolution and near-ground vertical resolution finer than $20 \mathrm{~m}$. Methods for temporal along with horizontal and vertical spatial nesting are demonstrated within the NWP model for maintaining forecast feasibility. It is shown that vertical nesting can improve the prediction of finer structures in near-ground temperature and velocity profiles, such as morning temperature inversions and low level jet-like features. Accurate representation of these features is shown to be important for modeling sound refraction phenomena and for enabling accurate noise assessment.

\footnotetext{
${ }^{*}$ Corresponding author

Email address: Stephen.Shaffer@asu.edu (S.R. Shaffer)
} 
Comparisons are made using the parabolic equation model for predictions with profiles derived from NWP simulations and from field experiment observations during mornings on November 7 and 8, 2006 in Phoenix, Arizona. The challenges faced in simulating accurate meteorological profiles at high resolution for sound propagation applications are highlighted and areas for possible improvement are discussed.

Keywords: Freeway Noise, Meteorological Profiles, Mesoscale Modeling PACS: $43.28 . \mathrm{Gq}$, 43.28.Bj, 43.50.Vt, 43.28Js

\section{Introduction}

Since early work of Reynolds [1, 2], the importance of atmospheric structure on sound propagation is well recognised[3, 4]. In a previous study[5], hereafter OSF09, the effects of measured near-ground profiles of temperature and wind speed on sound propagation from a highway noise source were quantified and a high sensitivity to temperature and wind profiles was found. For this reason it is desirable to accurately replicate temperature and wind velocity profiles in sound propagation models using either careful measurements or detailed simulations. Simulations are applicable for future situations as a forecast (derived from observations of an initial state at the current time or a future state based on models of global change), or for previous situations using either hind-casting (derived from observations of an initial state at a previous time) or reanalysis (hind-casting combined with periodic assimilation of in-situ data). Obviously, in combining the meteorological model with an acoustic model, the mode of forecasting requires additional modeling/forecasting of the acoustic sources which is not considered here. 
OSF09 used surface measurements coupled to Monin-Obukhov Similarity Theory (MOST) to derive near-surface meteorological profiles[6]. MOST is a technique commonly used for obtaining profiles from near-ground observations [7]. However, the appropriateness of such approaches for settings with varying terrain and land-cover must be viewed with caution because the theory is only suitable for flat horizontally homogeneous terrain and land-cover. Furthermore, stable conditions can lead to decoupling of the surface layer from dynamics aloft which can host rich complexity including intrusions, low level jets or katabatic/adabatic valley flows typical of cities set within mountainous terrain[8, 9]. The inadequacy of Monin-Obukhov scaling in the presence of a katabatic jet has been discussed previously for sloped terrain[10] as well as for flat terrain stable flows[11].

A second criticism of assuming MOST for sound propagation is that it is applicable only for mean profiles and hence will not capture transient atmospheric events that may influence sound propagation even from steady sources leading to strong fluctuations in sound levels at far field locations. Such transient atmospheric events have been reported in cities such as Salt Lake City, Utah[12] and Phoenix, Arizona[8], where morning[13, 14] and evening [15] transitions occur during frequent high pressure/weak synoptic forcing. Similarly, coastal cities, especially with adjoining mountains such as in California, have added influences of marine intrusions in the local dirunal circulation patterns[16, 17]. However, even with homogeneous yet gently sloping terrain in the Great Plains, transient events limit effectively predicting acoustic propagation with only a single sound speed profile[18].

There have been scarce previous studies where real regional-scale mete- 
orological conditions are simulated for use in near-ground acoustic models for noise pollution. Most notably, Hole and Hauge[19] predicted the influence on transmission loss of a $100 \mathrm{~Hz}$ source due to a temperature inversion breakup during low wind conditions. They derived vertical profiles using the Fifth-generation Mesoscale Model (MM5)[20], where their highest resolution domain had a $500 \mathrm{~m}$ horizontal grid spacing with 31 vertical levels, 6 of which being below $100 \mathrm{~m}$ Above Ground Level (AGL). In the same paper, the authors explored special considerations for the influence of topographic shading on the surface energy budget and concluded that doing so improved prediction of temperature profiles in comparison with balloon-tethersonde observations. Such an improvement potentially makes such model applications for sound predictions more reliable. Other efforts focus on large-eddy resolving scales (horizontal length scales less than $500 \mathrm{~m}$ ) and are beyond the scope of the present manuscript[21].

In this paper, we employ the Weather Research and Forecasting (WRF) model and software framework [22, 23], which is a successor to the MM5 model mentioned above. Like MM5, WRF makes use of horizontal nesting, which is a method of grid refinement wherein a child domain with increased horizontal resolution derives initial and lateral boundary conditions from a parent domain, thus making it possible to study detailed phenomena within a limited area without the computational expense of running all nests at the higher resolution[24]. However, unlike MM5, WRF has the added capability of refining the vertical grid resolution within a child domain. Doing so has demonstrated the ability to resolve dynamics not present in the coarser simulations, thus more closely predicting observations for phenomena within 
the atmosphere $[25,26,27,28]$.

We apply the same acoustic propagation model described in our previous paper[5] for effective sound speed derived from vertical profiles of temperature and velocity using a baseline configuration of the WRF model. We examine the degree to which the refractive effects of actual measured wind and temperature profiles can be represented by utilizing vertical nesting within WRF, in contrast to unrefined simulations, for deriving profiles below $400 \mathrm{~m}$ AGL. Such an investigation then enables us to judge how useful such NWP models might be in assessing environmental noise impact from near-ground sources. Field experiment data and subsequent results from the original paper are then used to evaluate the simulation improvements. We perform a reanalysis of the meteorological conditions for the November 2006 Arizona Department of Transportation (ADOT) field experiment using a $1 \mathrm{~km}$ horizontal grid as the finest domain. Diffraction and reflection effects from buildings are not incorporated into our models since they are not present in the meteorological code nor in the vicinity of the highway section of field experiments.

\section{Acoustic model}

The same acoustic model is used in this paper as that presented in our previous work[5], but using sound speed profiles derived from WRF simulations rather than observations. A brief description of the model is provided here. The two-dimensional vertical plane transverse to the highway is divided into two sub-domains: a near-field domain where refractive effects are

ignored, and a far-field domain beyond. The traffic noise is represented by 17 monofrequency coherent line sources, with each frequency representing a 
standard one-third octave band. Within the near-field domain where a homogeneous atmosphere is assumed, a Green's function solution adapted from the work of Chandler-Wilde and Hothersall[29] for a line source above a horizontal plane of spatially varying acoustic impedance is used. The Green's function solution is solved to obtain a vertical profile of the acoustic pressure field at the edge of the roadway. The same virtual line source strengths and positions as derived in our previous paper[5] were applied for each case.

The acoustic pressure profile is then used as the starting field for a wideangle parabolic equation (PE) model that incorporates a varying vertical effective sound speed profile[30, 31]. This sound speed profile used in the PE model is derived from profiles of the wind component in the direction of propagation, $U^{\prime \prime}(z)$, and the potential temperature $T(z)$ in Kelvin. The effective-sound-speed profile is then given by,

$$
C_{\text {eff }}(z)=>\overline{V R T(z)}+U_{,(z)}
$$

where $V$ is the ratio of specific heats, and $R$ is the gas constant. The first term in Equation 1 is the adiabatic sound speed, $C_{\text {ad }}$, and the second term accounts for motion of the medium in the direction of propagation. A key assumption within the PE model is that the medium is stationary, which this form of $C_{\text {eff }}$ enables. Within the PE model, a Crank-Nicholson scheme is used to march the starting acoustic field horizontally out to the far-field and an exponentially attenuating layer at the top third of the domain, combined with the Sommerfeld radiation condition[31, 32, 33], is applied to prevent artificial numerically reflected waves. 
For consistency of comparison with our previous work, the ground boundary condition is represented by the Delany and Bazley impedance model[34] with flow resistivities representative of asphalt $\left(\sigma=3 \times 10^{7} \mathrm{~Pa} \mathrm{~s} \mathrm{~m}^{2}\right)$ for the near-field ray domain, and hard sandy soil $\left(\sigma=4 \times 10^{5} \mathrm{~Pa} \mathrm{~s} \mathrm{~m}^{2}\right)$ for the PE domain. The PE model is run for each single one-third octave band. Stability and accuracy of the PE model requires 10 points per wavelength, so high frequencies become costly to compute. However, only 17 bands are needed since each frequency's contribution to the sound pressure level is A-weighted[5]. Acoustic model output for each frequency band is then interpolated onto a uniform $0.25 \mathrm{~m}$ by $0.25 \mathrm{~m}$ grid and summed in the usual fashion (given below) to obtain an overall A-weighted sound pressure level.

\section{WRF numerical experiment}

\subsection{Study Domain of Coupled Acoustic Model}

The vertical profiles derived from the WRF simulation were evaluated against those taken during the previous field experiments on freeway noise propagation during morning transition[5] conducted during the morning hours of November 7 and 8, 2006 along the Phoenix Loop 202 highway in Mesa, Arizona near coordinates $33.48240^{\circ} \mathrm{N}, 111.76338^{\circ} \mathrm{W}$; the exact location is highlighted in Figure 2 (discussed in +3.3). Instruments deployed included microphones, SOund Detection And Ranging (SODAR) with Radio Acoustic Sounding System (RASS), and sonic anemometers positioned on one meteorological tower and two tripods. Three cases in the observational dataset were selected in the previous paper because they exemplified varying levels of shear and stratification and these cases are specified in Table 1. The mea- 
Table 1: Specific cases used from OSF09. Note: MST=UTC-7 and the sunrise/set times for these dates was 0653/1730 MST. See timeline in Figure 1c.

sured wind and temperature profiles obtained in these cases are compared here to profiles computed using WRF in terms of their impact on long-range noise propagation.

\subsection{WRF Model Configuration}

As noted previously, for applications such as highway acoustics studies, we seek to produce vertical profiles of temperature and horizontal velocity in the lowest $400 \mathrm{~m}$ above ground with resolution sufficient to contain salient features necessary for deriving representative acoustic fields. Towards this goal, we use nested simulations with final resolutions finer than what is typically employed for real-time forecasting. The benefit of using a new method of vertical refinement of a child domain, described below, is investigated here. Such refinement is adopted as opposed to increasing near-surface resolution, which would have added extra model levels to all domains. Four telescoping 


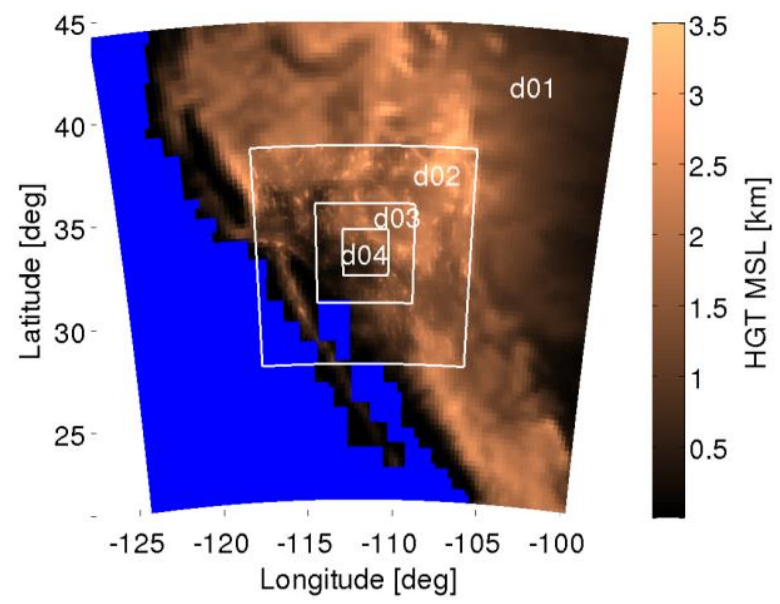

(a)

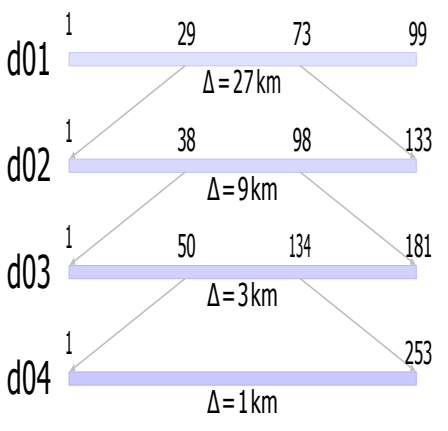

(b)

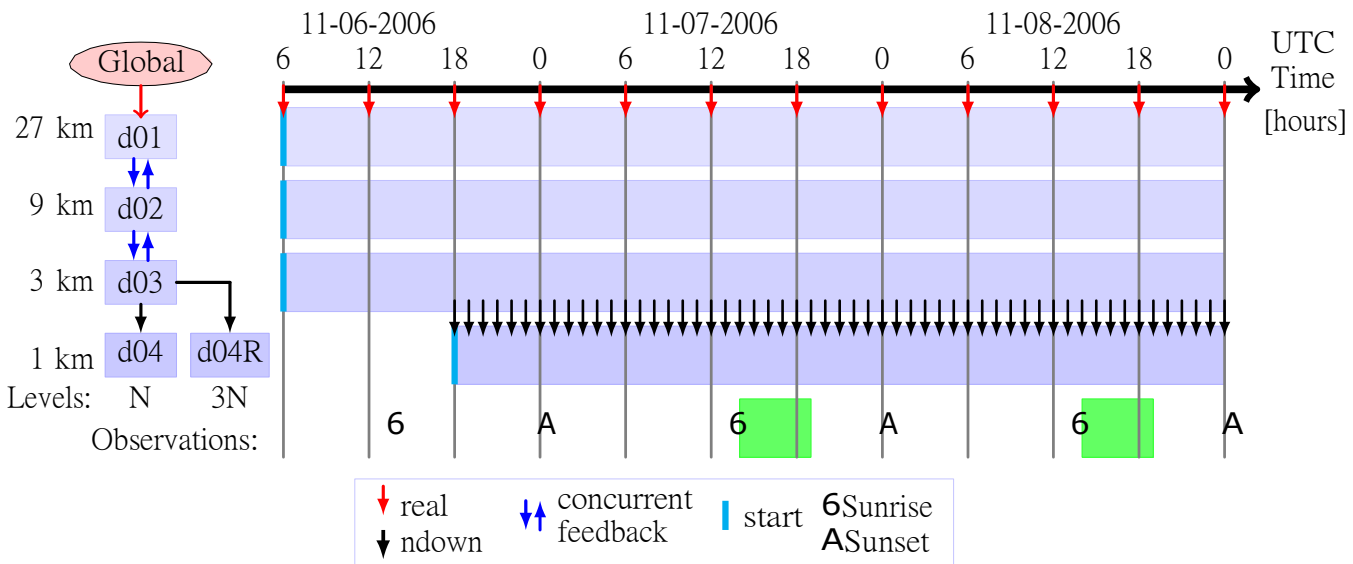

(c)

Figure 1: (Color online) Schematic of WRF Model Domain: (a) Map of terrain height in $\mathrm{km}$ above mean sea level showing outer perimeter of 4 telescoping nests centered on Phoenix, Arizona. (b) Schematic of nesting by staggered horizontal grid index with nest label $\mathrm{d} 0 \mathrm{X}, \mathrm{X}=1-4$, and horizontal grid spacing in $\mathrm{km}$. (c) Schematic of nesting feedback, parent data source, method of nesting and refinement of vertical levels, with corresponding timeline schematic for each nest depicting lateral boundary update and nest initialization times along with observational periods (shaded). 
nested domains, shown in Figure 1a and Figure 1b, centered near Phoenix Arizona, at coordinates $33.45{ }^{\circ} \mathrm{N}, 112.074{ }^{\circ} \mathrm{W}$, with horizontal grid resolutions of $27,9,3$ and $1 \mathrm{~km}$ were used. The model top is set to $50 \mathrm{mbar}(\approx 20$ $\mathrm{km}$ above mean sea level).

The vertical coordinate used in WRF is based on terrain-following hydrostatic pressure and levels are non-uniformly distributed, being more closely spaced near the model bottom and top. We test refinement of vertical resolution applied for the fourth nest which has $1 \mathrm{~km}$ horizontal resolution, from a modest 27 initial vertical levels within the parent domains (d01 to d03), to a domain with 81 vertical levels (d04R). One-way vertical refinement is achieved with the WRF program ndown.exe for a vertical refinement factor of 3, which subdivides each initial vertical level spacing while satisfying smoothness of pressure[25]. An unrefined $1 \mathrm{~km}$ nested domain (d04) was used as a control, being initialized in a similar fashion except it had the vertical refinement factor set to 1 . The schematic in Figure 1c illustrates how d04 and d04R derive lateral boundary conditions from $1 \mathrm{hr}$ output of d03. A 12 h time-interval was used between the start time of the first three domains ( $\mathrm{d} 01$ to $\mathrm{d} 03$ ) and the initialization of the finest nest (d04 or d04R). This time interval is needed for spin-up of the parent domains [35], and also reduces computational overhead.

The simulations are for a $66 \mathrm{~h}$ period, initialized using the $1.6 \mathrm{~h}$ Final (FNL) global analysis data [36] beginning at 06:00 UTC on November 6th 2006, as shown in the timeline schematic in Figure 1c. This allows a $20 \mathrm{~h}$ spin-up time before the first observational period of the field experiment for the refined nest, which is nested in time by $12 \mathrm{~h}$ from the model initialization 
of the outer three domains. Two-way feedback was used between the first three nests, which were run in concurrent mode. Hourly output was recorded for the entire period, with $5 \mathrm{~min}$ output for the $3 \mathrm{~km}$ and $1 \mathrm{~km}$ domains. The first domain used a $135 \mathrm{~s}$ timestep and a parent-to-child timestep ratio of 1:3 was used for all except the $1 \mathrm{~km}$ domain, where increased resolution necessitated a $4 \mathrm{~s}$ timestep due to Courant number stability constraints [24]. The $4 \mathrm{~s}$ timestep was also used in the control domain.

All of the model parameterizations were held fixed to the following settings. Physical processes involving moisture were modeled using the WRF single-moment microphysics 3-class scheme [37]. Standard radiation schemes of (RRTM) long-wave [38] and Dudhia short-wave [39] were called every 9, 3, 1 and 1 min for domains d01 through d04, respectively. The Kain-Fritsch cumulus parameterization for unresolved convective processes [40] was used only for the outer domain, being called every $5 \mathrm{~min}$. We use 5th (3rd) order horizontal (vertical) advection methods. The split-step scheme uses 4 acoustic timesteps per model timestep for each domain[41, 42]. The base temperature was set to $300 \mathrm{~K}$ and the non-hydrostatic option was used with no vertical damping imposed.

The geographic land-use classifications and terrain elevations were obtained from the U.S. Geological Survey 24-category 300 resolution data. The legacy MM5 5-layer thermal diffusion land surface model[20] was employed to represent ground temperature response to solar forcing. The coupling between the ground and the atmosphere was parameterized by the MM5 surface layer similarity scheme, which is a form of MOST applied to the first model level, and is connected to the Yonsei University planetary boundary 


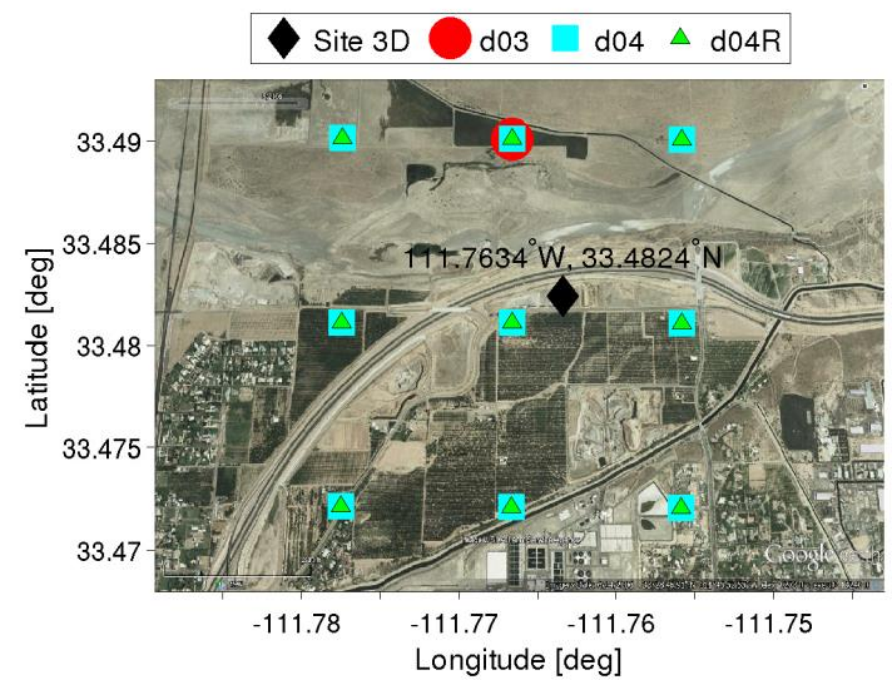

Figure 2: (Color online) Google Earth image (circa 6/2006) near approximate site location (diamond) and ensemble of WRF Arakawa-C grid cell center locations used in analysis for $3 \mathrm{~km}$ (d03, circle), and $1 \mathrm{~km}$ (d04, squares; $\mathrm{d} 04 \mathrm{R}$, triangles) horizontal resolution domains.

layer scheme[43]. The Yonsei University scheme is a non-local method of turbulence closure and handles the vertical mixing due to unresolved eddies. Horizontally, a 2nd-order diffusion parametrization for turbulence and mixing and a horizontal Smagorinsky 1st order closure scheme are implemented to account for subgrid processes.

\subsection{WRF profile selection and coupling with acoustic model}

The WRF model uses an Arakawa-C grid where scalar variables are at grid cell centers, and vector variable components are on a staggered grid at cell faces. Scalars (e.g. temperature), and horizontal vector components, are at the half-mass level (hereafter level), one-half of the full-mass level (around $60 \mathrm{~m}$ for 27 vertical levels). Values at grid centers are interpreted as 

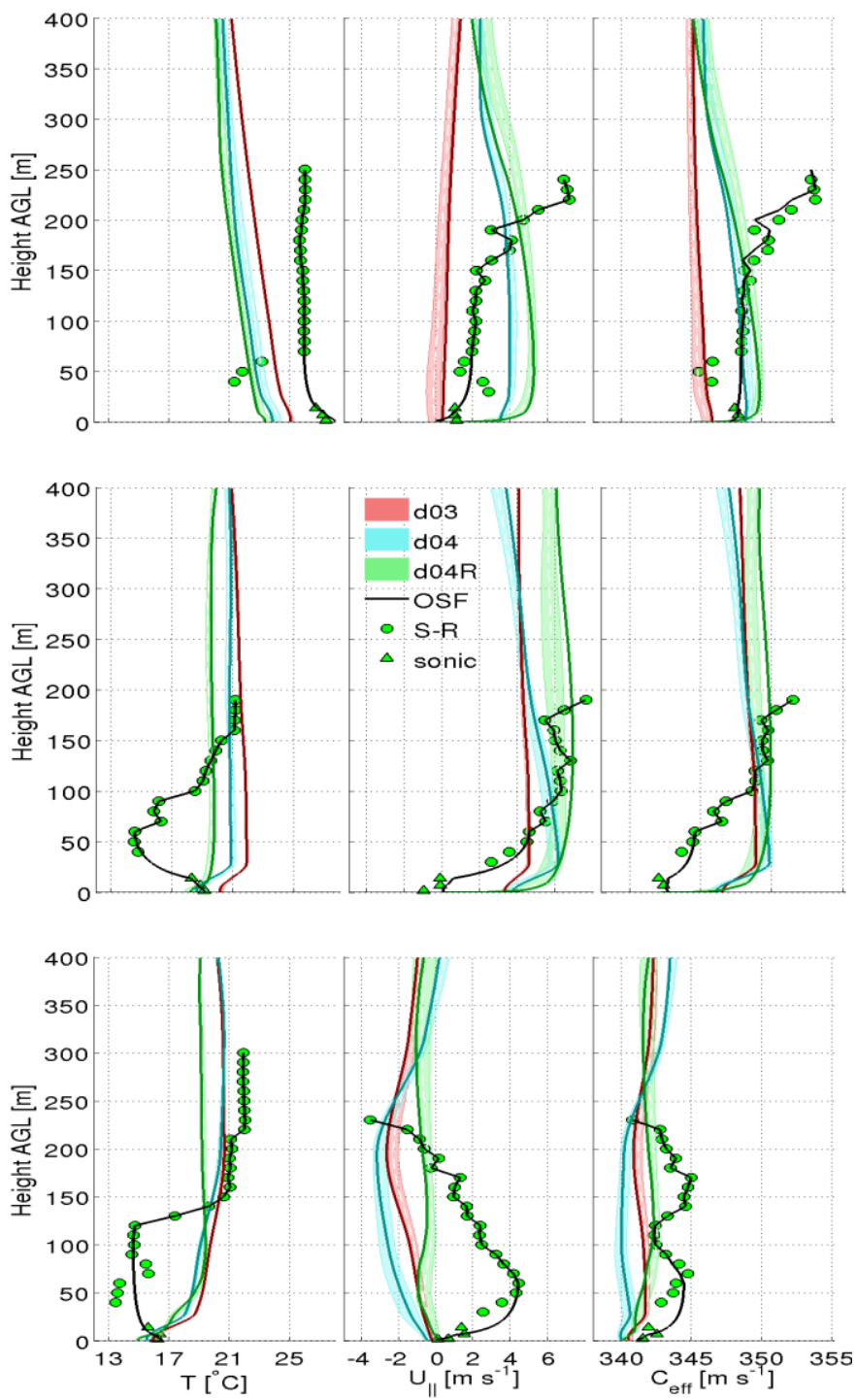

Figure 3: Ensemble of derived WRF profiles of temperature (left column), velocity component parallel to propagation direction (middle column), and effective sound speed (right column), for OSF09 case A (top row), case B (middle row), and case $C$ (bottom row). Shown are curves for domains d03 (red), d04 (cyan), and d04R (blue), at the beginning of the respective observational period at closest site location, and mean (white dashed) with \pm 1 standard deviation (shaded) for the ensemble over all 5 min output times at locations shown in Figure 2 during each case. The green circles and triangles are SODAR-RASS and sonic anemometer observations, respectively, with the black curves being the respeđBive OSF09 theoretical profiles derived from observations. 
representative of the cell volume average. Thus, unstaggered velocities at the grid centers are obtained by a simple arithmetic average between adjacent cell faces.

Shown in Figure 2 are the WRF computational domain non-staggered Arakawa-C grid (cell center) coordinates for the 3 and $1 \mathrm{~km}$ domains in the neighborhood of the observational site location used in our analysis. These coordinates are overlaid on a historical Google Earth image to illustrate the land use for the study area near the date of the study. Based upon these grid locations and with the highway running primarily East-West, profiles of potential temperature and the $V$ velocity component (positive to north) are extracted to generate the input $C_{\text {eff }}(z)$ profiles used in the PE model for propagation transverse to the highway. As the field experiment in our previous paper[5] typically measured crosswinds from the North and examined downwind impacts, we will look here also at propagation downwind only.

In constructing profiles for the acoustic model, we examine each location in latitude-longitude and time separately. Doing so enables us to check for phase offsets in the timing or localization of phenomena such as low-level jet-like features. In order to directly compare the profiles derived from WRF with the 20 min time-averaged profiles from experimental observations [5], an ensemble of representative profiles from the model domain near the observational site was built by using model output at 5 min intervals during the 20 min observational period on the de-staggered $1 \mathrm{~km}$ grid points close to the site, as shown in Figure 2. This is intended to capture both the mean profile shape and to estimate variance in the derived profiles. 
Profiles are derived using the geopotential height, given by,

$$
z=\frac{\varphi}{g}-h
$$

where the height above ground level, $z$, is related to the surface elevation $h$, gravitational acceleration $g=9.81 \mathrm{~m} \mathrm{~s}^{-2}$, and the geopotential, $\varphi$. The model-level temperature values were obtained by,

$$
T=\theta{\frac{P}{P_{0}}}^{-R / c_{p}},
$$

where $\theta=\theta^{t}+\bar{\theta}$ is potential temperature with base value $\bar{\theta}=300 \mathrm{~K}$, and prognostic perturbation value $\theta^{t}$. $P$ is total atmospheric pressure, $P_{0}=10^{5}$ $\mathrm{Pa}$ is a reference pressure, and $R / c_{p}$ is the ratio of the gas constant, $R=$ $8.3144 \mathrm{~J} \mathrm{~mol}^{-1} \mathrm{~K}^{-1}$, to the specific heat at constant pressure for dry air, $c_{p}=29.07 \mathrm{~J} \mathrm{~mol}^{-1} \mathrm{~K}^{-1}$.

The WRF model considers the surface layer as a constant-flux layer linking the land-surface and the first model level, employing similarity theory to obtain diagnostic quantities based upon surface fluxes[42]. However, to allow a fair comparison with the previous method to derive profiles between measurements near-surface and aloft[5], we likewise combine the WRF diagnostic $2 \mathrm{~m}$ temperature, $T_{2}$, and diagnostic $10 \mathrm{~m}$ northward wind velocity component, $V_{10}$, with model level values. The near-ground theoretical wind and temperature profiles, along with prognostic model-level values, are then interpolated for input into the acoustic model using a monotonic cubic spline to a $0.25 \mathrm{~m}$ resolution below $10 \mathrm{~m}$ and a $2 \mathrm{~m}$ resolution above. The acoustic model then subsequently interpolates further for each frequency band to the 
requisite grid spacing of ten-points per wavelength.

The temperature profile is constructed by holding the value below $2 \mathrm{~m}$ constant at $T_{2}$, and a linear fit is used to interpolate from $2 \mathrm{~m}$ to the lowest model level, $z_{1}$. A near-ground logarithmic wind profile was constructed [6] of the form,

$$
V(z)=\operatorname{sgn}\left(V_{0}\right) \frac{u^{*}}{K} \log { }^{-} z_{z_{0}^{-}}^{-}+V_{0}
$$

with $V_{0}$ based on either $V\left(z_{1}\right)$, or $V_{10}$, depending on the position of the first level $z_{1}$ in the simulation via the following rule:

$$
\begin{aligned}
& \text { if } z_{1}<15 \text { [m] } \quad V_{0}=V\left(z_{1}\right) \quad, \quad z_{0}=z_{1} \\
& \text { else } \quad V_{0}=V_{10} \quad, \quad z_{0}=10[\mathrm{~m}] \text {. }
\end{aligned}
$$

Here, $k=0.4$ is the Von Karman constant, $u^{*}$ the friction velocity, $z_{0}$ represents the surface model roughness length, and $\operatorname{sgn}\left(V_{0}\right)=V_{0} \backslash V_{0} \mid$ ensures that the profile is in the correct direction. Since $\log \left(z / z_{0}\right)$ diverges as $z \rightarrow 0$, we restrict derived velocity profiles from reversing direction near the ground. This restriction is achieved by setting $V(z)=0$ for $0 \leq z \leq z_{0} 10^{-\left|V_{0}\right| \kappa / u^{*}}$. 


\section{Methods of analysis of acoustic model predictions}

The spectral components for each one-third octave frequency band $f_{n}$, are defined by,

$$
L_{A, f_{n}}(x, z)=10 \log _{10}\left(.5|p(x, z)|^{2}\right)+20 \log _{10} S_{0, f_{n}}
$$

for acoustic pressure $p(x, z)$ with a virtual source strength given by $S_{0, f_{n}}$. Since the observed values used within the optimization procedure described in our previous work[5] were A-weighted, so will be the source strengths and resultant spectral components. The $L_{A, f_{n}}$ results for all frequency bands are then interpolated onto a uniform grid (which here has a spacing of $.25 \mathrm{~m}$ ) and combined to obtain the A-weighted Sound Pressure Level (SPL) given by,

$$
L_{e q}=10 \log _{10}{ }_{n=1}^{17} 10^{L_{A, f_{n}} / 10},
$$

for the 17 standard one-third octave bands between $63 \mathrm{~Hz}$ and $2500 \mathrm{~Hz}$, inclusive.

For a quantative analysis of the influence of different effective sound speed profiles $C_{\text {eff }, j}$, we examine the relative SPL with respect to the point $x_{0}=50$ $\mathrm{m}$ range at $z=1 \mathrm{~m} \mathrm{AGL}$, defined for an ensemble of profiles indexed by $j$ as,

$$
\Delta L_{j}(x, z=1)=L_{e q, j}(x, z=1)-L_{e q, j}\left(x=x_{0}, z=1\right) .
$$

Furthermore, PE results for equivalent stationary homogeneous (non-refracting) atmosphere cases, wherein the vertical profiles of crosswind velocity and temperature are set to zero and the ground value, respectively, are used to cor- 
rect for each ensemble member having different baseline sound speeds. For non-refracting cases the $L_{e q}$ value decays due to geometrical spreading proportional to inverse distance, $L_{e q} \propto x^{-1}$, for a line source. The equivalent relative SPL in the non-refracting atmospheric case (superscript $N$ ) can be written as,

$$
\Delta L^{N}=a\left(x^{-1}-x_{0}^{-1}\right) .
$$

The coefficient, a, will only depend upon the ground-level sound speed (or reference Helmholtz number) for each non-refracting case, which is explicitly denoted by $a=a\left(C_{0, j}\right)$. Thus, the non-refracting case relative SPL between an ensemble member (subscript $j$ ) with respect to an arbitrary reference ensemble member (subscript $r$ ), are related by,

$$
\frac{\Delta L_{r}^{N}}{\Delta L_{j}^{N}}=\frac{a\left(C_{0, r}\right)}{a\left(C_{0, j}\right)}
$$

This non-refracting case relationship enables a fair direct comparison of the relative SPL for an ensemble member, subscript $j$, with respect to an arbitrary reference member, $r$, viz,

$$
\Delta L_{j, r}={\stackrel{\Delta}{\Delta L_{j}^{N}}}_{\frac{r}{N}} \Delta L_{j},
$$

arising from PE model predictions using different input $C_{\text {eff }, j}$ profiles. 


\section{Results}

\subsection{Influence of horizontal and vertical nest resolution on simulated meteo- rological profile features}

Firstly we present the vertical profiles of temperature $(T)$, wind component parallel with propagation direction $\left(U^{\prime \prime}=-V\right)$, and effective sound speed ( $C_{\text {eff }}$ ), derived from WRF and used for input into the acoustic model. These profiles are shown in Figure 3 for OSF09 cases A, B and C, with main features distinguishing observed profile cases summarized in Table 1. The instantaneous profile at the first time of WRF output during the $20 \mathrm{~min}$ interval at the nearest horizontal grid location (see Figure 2), which will be employed in later examples of acoustic model output, is also shown for each of the domains d03, d04 and d04R.

Additionally, the ensemble spreads ( \pm 1 standard deviation) are shown in Figure 3 as shaded regions for each domain, where the ensemble consists of all $5 \mathrm{~min}$ output of instantaneous realizations at profile locations indicated in Figure 2 during the $20 \mathrm{~min}$ interval. Each ensemble represents the same spatial and temporal footprint between the different resolution simulation domains, and enables evaluation of spatial and temporal phase errors for a given ensemble member with respect to a representative mean profile within the site neighborhood during the observation period. For comparison, $20 \mathrm{~min}$ averaged SODAR-RASS and sonic anemometer observed data obtained from the original experiments[5] are also plotted, along with the OSF09 theoretical curves.

Root-Mean Square Errors (RMSE)[44] were derived between each ensem- 
Table 2: RMSE values of profiles for $T, V\left(=-U^{\prime \prime}\right)$, and $C_{\text {eff, }}$, shown in Figure 3, using interpolated profiles at $10 \mathrm{~m}$ AGL and between $40 \mathrm{~m}$ and $190 \mathrm{~m}$ AGL at $10 \mathrm{~m}$ increments (valid SODAR-RASS levels for all cases), between observations and ensemble mean for each domain, grouped by OSF09 meteorological case. Also for Eastward velocity component (U) and horizontal wind magnitude $\left(\left|U_{H}\right|\right)$. For relative $\operatorname{SPL}(\Delta L)$ using the ensemble mean of curves shown in Figure 10 over the entire $600 \mathrm{~m}$ range. 
ble mean profile and the corresponding OSF09 profile, by interpolating to 10 $\mathrm{m}$ height and $10 \mathrm{~m}$ increments from $40 \mathrm{~m}$ height to $190 \mathrm{~m}$ height (limit of SODAR observations), which are summarized in Table 2. Also given in Table 2 are the RMSE values at these same heights for the $U$ velocity component (positive to east) and horizontal wind magnitude $\left|U_{h}\right|=\left(U^{2}+V^{2}\right)^{1 / 2}$. Note that $U$ is perpendicular to the PE model propagation direction and so was not used in deriving the $C_{\text {eff }}$ profile. These additional terms enable assessing for wind direction errors within the entire profile, when RMSE for $\left|U_{h}\right|$ is smaller than for each component.

Case A in Figure 3 (top), at 1040 MST ( $\approx 4 \mathrm{~h}$ after sunrise), observations show that an unstable layer has formed in the lowest $300 \mathrm{~m}$, with wind shear only present above $150 \mathrm{~m}$. An underprediction bias for all domains is present in predicted temperature, with a $2.4{ }^{\circ} \mathrm{C}$ RMSE at $3 \mathrm{~km}$, and larger for the $1 \mathrm{~km}$ domains. The $\mathrm{V}$-component winds were underpredicted in the $3 \mathrm{~km}$ simulation but overpredicted at $1 \mathrm{~km}$ resolution up to the observed shear layer at $150 \mathrm{~m}$, with no corresponding increase in predicted wind speed above $150 \mathrm{~m}$. Meanwhile, horizontal wind magnitude error was reduced at 1 $\mathrm{km}$ compared to $3 \mathrm{~km}$ resolution, and further reduced by vertical refinement. Also, d04R wind component RMSE values indicate a direction bias. The bias error in constituent terms of $C_{\text {eff }}$ partially cancel when constructing profiles, which show reduced RMSE for both $1 \mathrm{~km}$ domains compared to $3 \mathrm{~km}$.

For case B in Figure 3 (middle), at $0740 \mathrm{MST}$ ( $\approx 1 \mathrm{~h}$ after sunrise), observations indicate a temperature inversion, warming by nearly $7{ }^{\circ} \mathrm{C}$ from $60 \mathrm{~m}$ to $160 \mathrm{~m}$ AGL, also with a warm surface creating an unstable layer up to $\approx 100 \mathrm{~m}$ AGL. Wind shear is also present in the same height range, with 


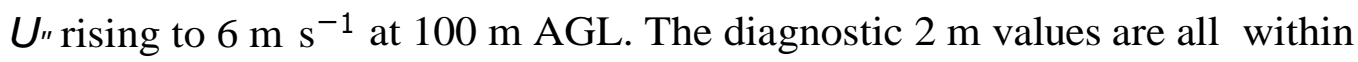
$2{ }^{\circ} \mathrm{C}$ of observations, and better represented at $1 \mathrm{~km}$ than at $3 \mathrm{~km}$. However, the lowest prognostic values all have considerable error below $100 \mathrm{~m}$ AGL, failing to capture the observed temperature inversion.

For all domains, the observed temperature variations for the lowest RASS range gates are not well reproduced, with overprediction bias of $\approx 4.5^{\circ} \mathrm{C}$ at $50 \mathrm{~m}$ AGL for d04R, and increasing bias for coarser resolution domains. Furthermore, the presence of any near-ground temperature inversion in the derived profiles for the unrefined domains is due to the fit between $T_{2}$ and $T\left(z_{1}\right)$, which could change with bias in either component. The vertically refined profiles, however, indicate an inversion but not at the same height or magnitude as in observations, and only with the lowest few model levels.

Agreement for $U^{\prime}$ between WRF and observed profiles is not encouraging. The d04R $U^{\prime \prime}$ profile has closest agreement with observations, showing a gradual shear, whereas $U^{\prime \prime}$ derived from d04 has a kink where the profile interpolated from the $10 \mathrm{~m}$ value meets the first model level. The $U^{\prime \prime}$ RMSE values are comparable for all domains, being between $1.5-1.8 \mathrm{~m} \mathrm{~s}^{-1}$. The RMSE values also indicate directional errors, where d04R performed best in terms of both reduced errors for wind components and wind speed. However, these profiles combine to produce an incorrect $C_{\text {eff }}$ profile below $100 \mathrm{~m}$ AGL for all domains.

Case C in Figure 3 (bottom), at $0740 \mathrm{MST}$ ( $\approx 1 \mathrm{~h}$ after sunrise), seems to yield the worst reproduced simulated profiles. The temperature in case C seems quite well reproduced only between 150-210 m AGL for both the unrefined $1 \mathrm{~km}$ and $3 \mathrm{~km}$ domains. Yet, observations indicate a nearly 6 
${ }^{\circ} \mathrm{C}$ temperature change within the $30 \mathrm{~m}$ just below this height, which is not captured at all by the model. The modeled $2 \mathrm{~m}$ values are within 1 ${ }^{\circ} \mathrm{C}$, but then the model exhibits a low inversion of $4{ }^{\circ} \mathrm{C}$ over $50 \mathrm{~m}$, then a more gradual inversion of 2-3 ${ }^{\circ} \mathrm{C}$ over the next $150 \mathrm{~m}$, rather than being unstable for the first $140 \mathrm{~m}$ followed the aforementioned strong inversion. The observations of $U^{\prime \prime}$ indicate a $4.5 \mathrm{~m} \mathrm{~s} \mathrm{~s}^{-1}$ jet with local maxima near a height of $50 \mathrm{~m}$. However, all domains indicate flow in the opposite direction for this velocity component, with a weak $-1 \mathrm{~m} \mathrm{~s}^{-1}$ local maxima in d04R near this height, whereas d04 indicates a local maxima nearly $-3 \mathrm{~m} \mathrm{~s}^{-1}$ at $200 \mathrm{~m}$ AGL. Furthermore, the observations indicate a reversing of direction above $200 \mathrm{~m}$, coincident with the temperature inversion height range, with speeds approaching $-4 \mathrm{~m} \mathrm{~s}^{-1}$ at the limit of the SODAR profile.

\subsection{Influence of increasing vertical resolution of meteorological simulation on predicted freeway noise propagation}

While the analysis of simulating meteorological profiles considered model grid cells in the observational site neighborhood for a stencil with side of $3 \mathrm{~km}$, at each $5 \mathrm{~min}$ output during the $20 \mathrm{~min}$ period, we now restrict to just the model grid cell containing the site location for each output time. One ensemble member of each meteorological case is shown for the $L_{A, f_{n}}$ and $L_{e q}$ plots, and the entire ensemble is shown for the $\Delta L$ plots. The acoustic model results presented here use the same acoustic source heights and strengths and same propagation model as for the respective cases in OSF09, but the vertical effective sound speed, $C_{\text {eff, }}$, is now obtained from the WRF derived profiles for the unrefined and refined 4th WRF domain discussed above (Figure 3). Comparisons are made with the propagation 
results obtained using experimentally observed profiles[5]. No atmospheric absorption has been applied to these results.

Individual spectral contributions to SPL at $1 \mathrm{~m}$ above the ground versus range, $L_{A, f_{n}}(x, z=1 \mathrm{~m})$, following Equation 5, are shown in Figure 4 to Figure 6. With the the total SPL against range and vertical height up to 50 m AGL, $L_{e q}(x, z)$, following Equation 6, shown in Figure 7 to Figure 9. The relative SPL, $\Delta L$, following Equation 10, is shown in Figure 10 for each case A-C. RMSE results for $\Delta L$ are also given in Table 2 for the entire $600 \mathrm{~m}$ range between observations and ensemble mean of $1 \mathrm{~km}$ domain predictions without and with vertical refinement.

\subsubsection{Case $A$}

In case $\mathrm{A}$, since the temperature profile gradients for the 4th domains are similar, the main differences in outcome will be produced by variations between the velocity profiles. The refined domain's wind profile is somewhat stronger with more shear near the ground. This aspect in the $C_{\text {eff }}$ profile leads to ducting close to the ground, most apparent at $500 \mathrm{~Hz}$ and above, with multiple loud and quiet interference extrema at the $1 \mathrm{~m}$ analysis height.

The $L_{e q}$ in this case fits the experimental observations more closely, and remains above $67 \mathrm{dBA}$ close to the ground up to a range of approximately $300 \mathrm{~m}$, similar to case A in our previous work[5]. It is unclear if the upward refracting behavior above $150 \mathrm{~m}$ in $C_{\text {eff, }}$ which is not as pronounced as in the unrefined domain, leads to the reduction in $L_{e q}$ beyond $300 \mathrm{~m}$. Whereas the weaker shear, yet still slightly downward refracting $C_{\text {eff }}$ for the unrefined domain, leads to sound focussing around $500 \mathrm{~m}$ range. Here, levels exceed 
67 dBA, mostly due to contributions from the octave bands between 100-250 $\mathrm{Hz}$, and above $1 \mathrm{kHz}$.

The aforementioned role of refinement is also manifested within the $\Delta L$. The unrefined domain's values decay with range to a minimum around 300 $\mathrm{m}$ range at $12 \mathrm{dBA}$ below $50 \mathrm{~m}$ range, before returning to just $5 \mathrm{dBA}$ loss at $600 \mathrm{~m}$ range. However, the refined domain displays an irregular and more gradual decay, yet still at a faster rate than for the observed profile. Yet, the RMSE statistic indicates that overall, the unrefined domain performed with nearly $1 \mathrm{dBA}$ reduced error over the refined domain.

\subsubsection{Case B}

For case $\mathrm{B}$, the near-ground shear and inversion were both seen to contribute to downward refraction within the $C_{\text {eff }}$ profiles for each domain below $100 \mathrm{~m}$ AGL. Based upon standard deviations of ensemble means, there is little difference between $C_{\text {eff }}$ profiles for these domains. However, We interpret the resultant near-ground acoustic field differences as being due to

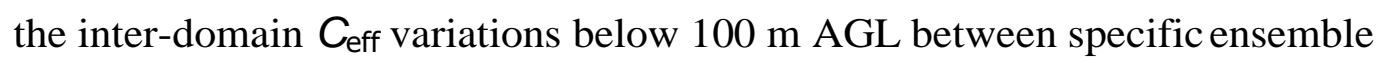
members. In particular, the fit to the lowest model level in $\mathrm{d} 04 \mathrm{R}$ (at $\approx 10$ $\mathrm{m}$ AGL), provides a stronger low-level wind shear than within $\mathrm{d} 04$, and creates stronger near-ground ducting of sound, with $500-1000 \mathrm{~Hz}$ bands again remaining dominant to larger ranges as in Case A. There is then a more gradual increase in the d04R $C_{\text {eff }}$ profile up to $\approx 100 \mathrm{~m}$ AGL. Whereas, the $C_{\text {eff }}$ for d04 peaks near the first model level $(\approx 30 \mathrm{~m})$, with a similar gradient, but more elevated and sustained than in d04R.

These $C_{\text {eff }}$ features lead to a near-ground quiet zone centered just after 
$300 \mathrm{~m}$ range before the SPL rises to well above $67 \mathrm{dBA}$. While this larger scale ducting continues to $600 \mathrm{~m}$ range, a smaller scale ducting closer to the ground is apparent in frequencies above $500 \mathrm{~Hz}$ after the first near-ground maxima. The decreasing proximity of maxima for higher frequencies supports an interference effect from the ducting by the $C_{\text {eff }}$ gradient. Meanwhile, frequency-dependent ground impedance would tend to differentially attenuate the reflected wave amplitude by frequency band, emphasizing the importance of the ground impedance model.

The $\Delta L$ for d04 shows that the locations of near-ground maxima are sensitive to the ensemble-member variability, while the higher frequency ducting beyond $300 \mathrm{~m}$ range is responsible for the spread in $\Delta L$ between ensemble members. Indeed, the unrefined sound field has two near ground constructive maxima in SPL in the first $600 \mathrm{~m}$ from the source whereas the original results based on experimental observations only produces one focusing just before $600 \mathrm{~m}$. The less severe shear and lack of any strong inversion in d04R produces down range $\Delta L$ similar to that observed in case $\mathrm{A}$, with $2 \mathrm{dBA}$ better overall RMSE compared to $\mathrm{d} 04$.

\subsubsection{Case C}

For case $\mathrm{C}$, all of the WRF-derived $T$ profiles indicate downward refraction below $70 \mathrm{~m}$ AGL, whereas $U^{\prime}$ would cause upward refraction, aside from d04R from 70-130 m AGL. These aspects combine within $C_{\text {eff }}$ indicating that below $30 \mathrm{~m}$ AGL, both d04 and d04R refract downwards, with d04R having a much stronger gradient in $C_{\text {eff }}$ in the lowest $10 \mathrm{~m}$ AGL. Suggesting that the method to interpolate between near-ground and first model level values, along with any bias in either value, plays a significant role. From $30 \mathrm{~m}$ AGL 
to around $100 \mathrm{~m} \mathrm{AGL}, C_{\text {eff }}$ profiles indicate that d04 will refract upward whilst d04R refracts downward. The observed profiles, however, show that the wind speed should be causing substantial downward refraction below 50 $\mathrm{m}$, whereas, the unstable temperature profile below $130 \mathrm{~m}$ AGL would cause upward refraction below $50 \mathrm{~m}$ AGL and otherwise be non-refracting. This scenario is reversed aloft with a second ducting region apparent in $C_{\text {eff }}$ between 50-150 m AGL. Here, the strong temperature inversion causes downward refraction from above, and the upper half of a low-level jet causes upward refraction from below.

The spectra and $\Delta L$ both indicate near-ground ducting, but with much more gradual refraction than previous cases, having large spacing between near-ground maxima. Ducting within d04R maintains the near-ground SPL above $73 \mathrm{dBA}$ out to $550 \mathrm{~m}$ from the source. Whereas d04 exhibits a quiet zone at all frequencies above $250 \mathrm{~Hz}$, with the $L_{\text {eq }}$ spatial map indicating a likely second near-ground maxima will occur beyond the PE model's range. All frequencies contribute to the increased SPL within d04R, with bands above $630 \mathrm{~Hz}$ exhibiting two near-ground focusing maxima with just under $300 \mathrm{~m}$ spacing at $1 \mathrm{~m}$ AGL. The $L_{e q}$ plot indicates that spacing of maxima will shift as $L_{A, f_{n}}$ is evaluated at different heights, up to $10 \mathrm{~m}$ AGL. Lower frequencies begin to exhibit a single quiet zone after $400 \mathrm{~m}$ range in $\mathrm{d} 04 \mathrm{R}$, and $300 \mathrm{~m}$ in d04, suggesting lower sensitivity than the higher frequencies to the first $10 \mathrm{~m}$ of the $C_{\text {eff }}$ profile. Lower frequency bands exhibit a near-ground ducting interference pattern similar to that noted for the high frequency bands in case B. The near-ground $\Delta L$ suggest that using the vertically-refined $C_{\text {eff }}$ profile of domains d04R more closely matched the experimentally derived 
profiles, with RMSE of $4.6 \mathrm{dBA}$ versus $10.7 \mathrm{dBA}$, despite the noted issues with $C_{\text {eff. }}$ 
Figure 4: Spectra of A-weighted one-third octave band center frequencies $\left(L_{A, f_{n}}\right)$ following Equation 5, versus range at $1 \mathrm{~m} \mathrm{AGL}$ for d04 (top), d04R (middle) and OSF09 (bottom). The $C_{\text {eff }}$ profiles are for the first of five $5 \mathrm{~min}$ output during the 20 min observational interval for case A. 

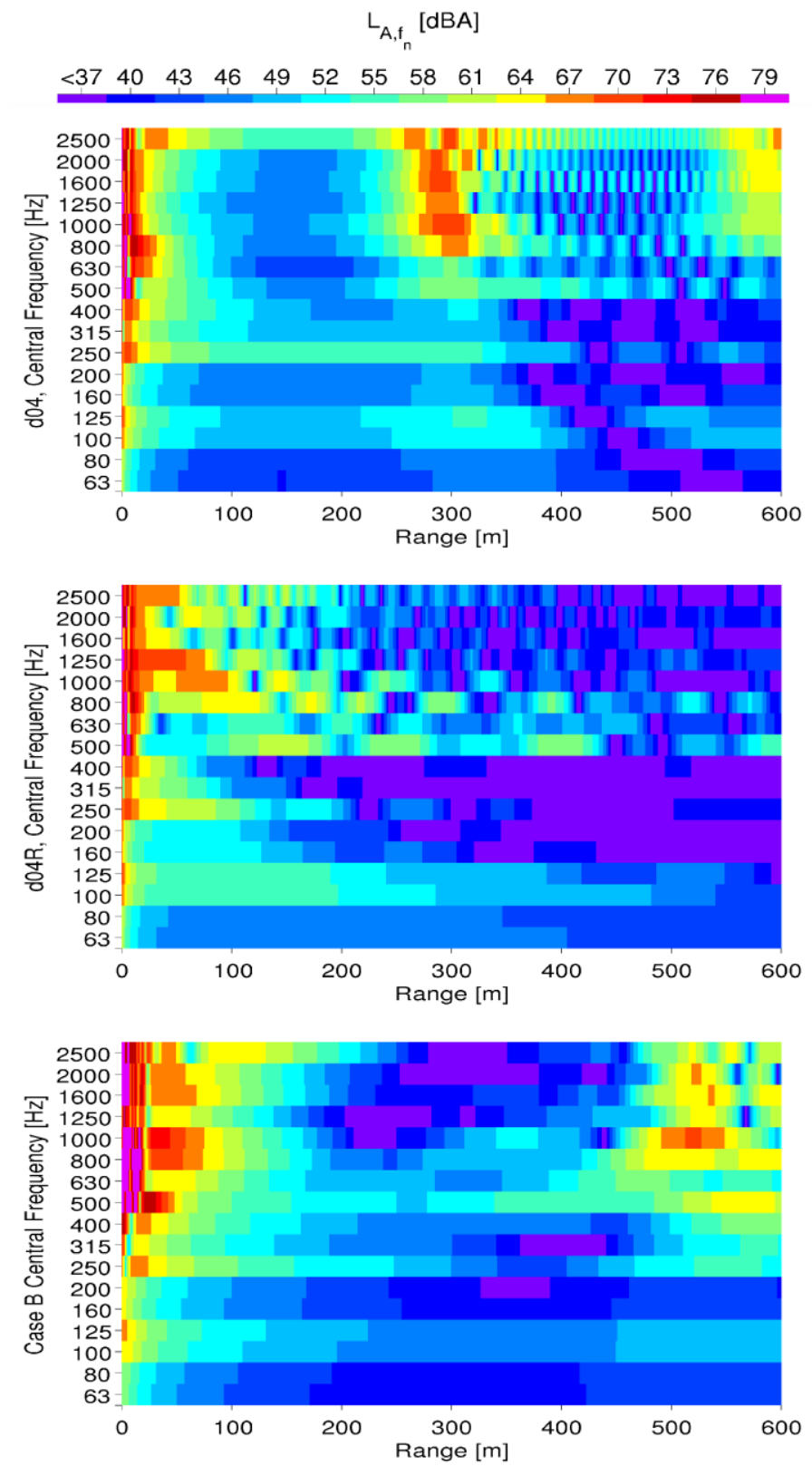

Figure 5: Same as for Figure 4 but for Case B. 

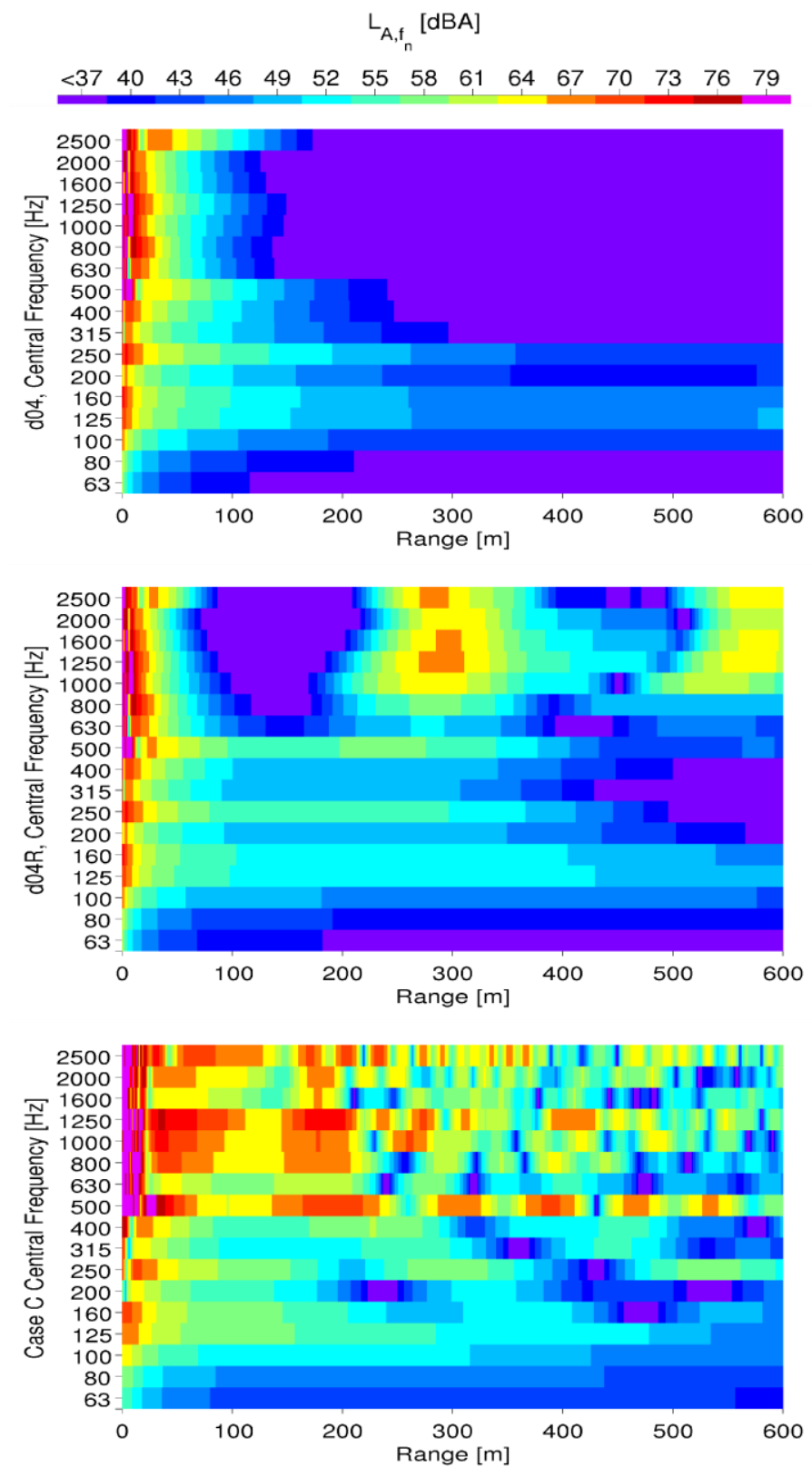

Figure 6: Same as for Figure 4 but for Case C. 

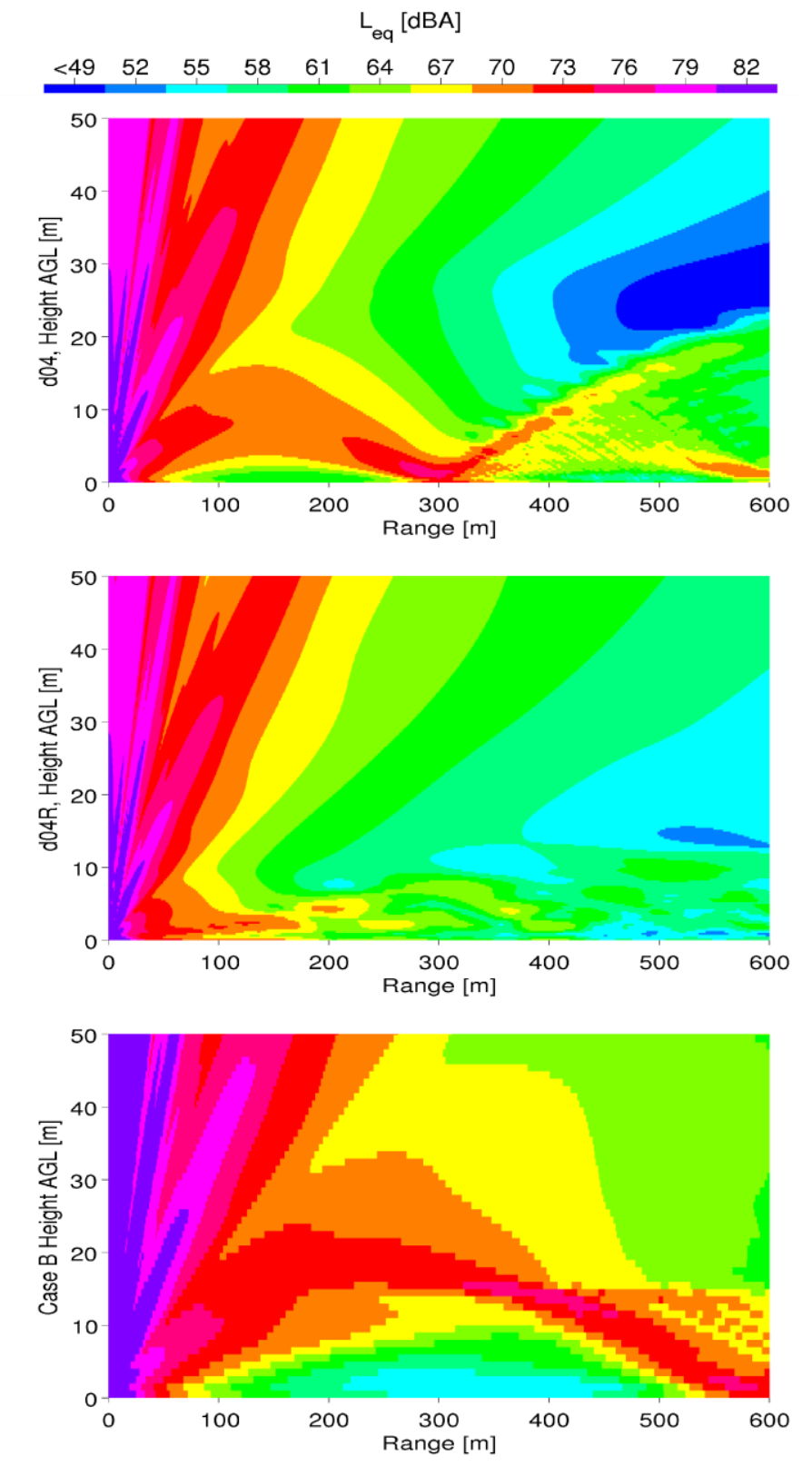

Figure 8: Same as for Figure 7 but for Case B. 

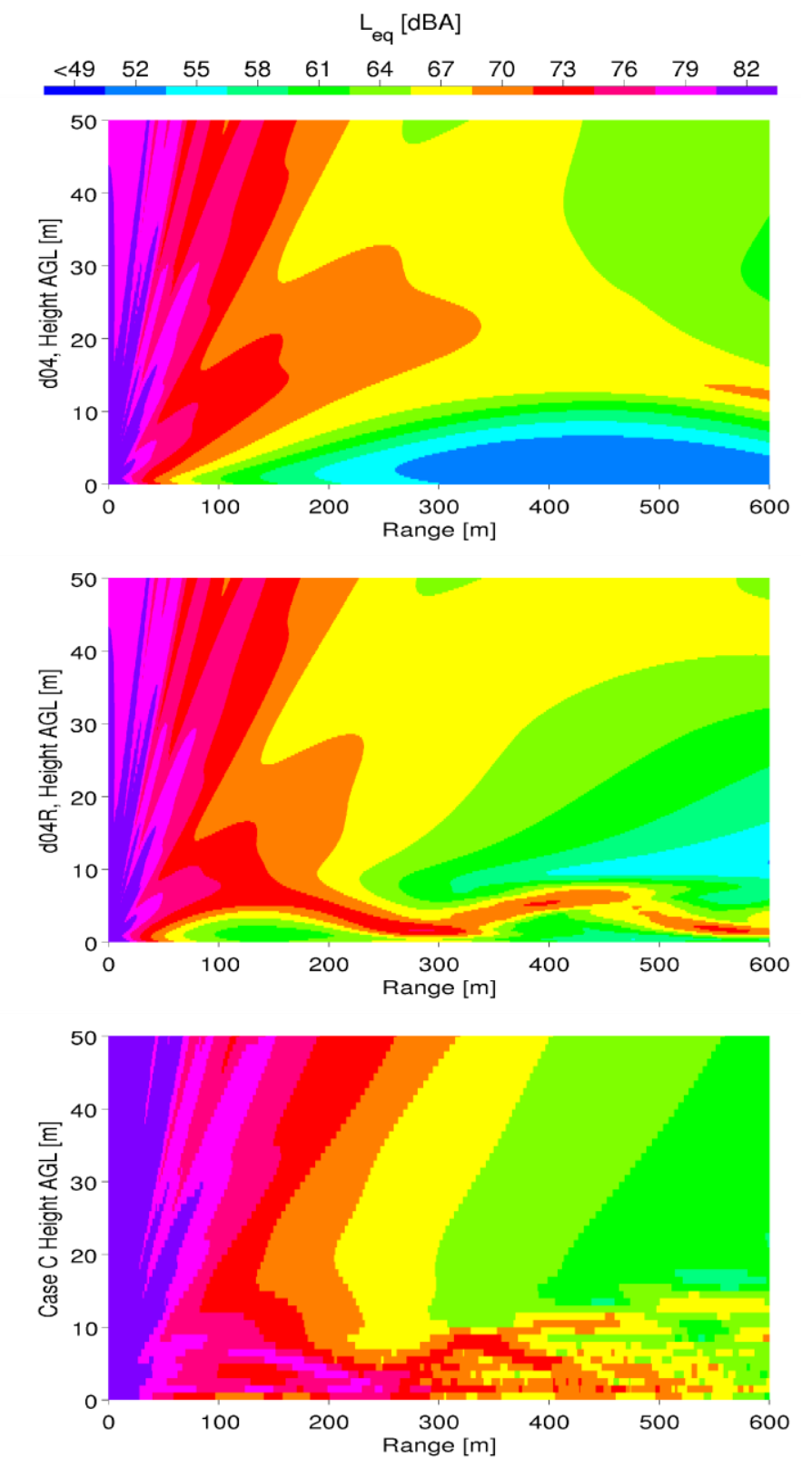

Figure 9: Same as for Figure 7 but for Case C. 
Figure 10: (Color online) Relative SPL $(\Delta L)$ with neutral case reference wavenumber correction following Equation 10, with respect to $50 \mathrm{~m}$ versus range at $1 \mathrm{~m}$ AGL for OSF09 case A (top) case B (middle) and case C (bottom) for OSF09 value (bold solid) non-refracting (dotted) and profiles derived from WRF domains d04 (bold dashed), d04R (bold dash-dot) at closest grid locations shown in Figure 2 for the output times corresponding to the $20 \mathrm{~min}$ observational periods given in Table 1 . No atmospheric attenuation has been included. 


\section{Discussion}

We have demonstrated a method for simulating meteorological profiles and assessed their suitability for use as input to an acoustic propagation model for freeway noise by examining three case studies in comparison with profiles derived from field measurements. We presented the method of vertical refinement for increasing meteorological simulation child domain vertical resolution, and discussed the influence of increasing the vertical resolution of our meteorological simulation on the predicted freeway noise propagation. We have provided a physically-motivated interpretation of emergent phenomenalogical qualities of spectra, total sound field, and relative SPL, resulting from features within simulated meteorological profiles. We discussed the influence of horizontal and vertical nest resolution on simulated meteorological profile features.

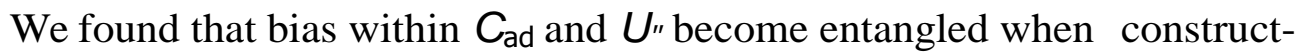
ing $C_{\text {eff, }}$ and may mask assessing the true capability and limitations of meteorological forecasting for acoustic application. We recommend investigating forecast skill requirements imposed by the sensitivity of acoustic model predictions of $L_{A, f_{n}}$ and $L_{e q}$ to variations within $C_{\text {eff }}$, especially below $100 \mathrm{~m}$ AGL. Overall RMSE of profiles suggest capability of simulating temperature profiles within around $3{ }^{\circ} \mathrm{C}$, wind speed profiles within around $2 \mathrm{~m} \mathrm{~s}^{-1}$, and $C_{\text {eff }}$ profiles around $2 \mathrm{~m} \mathrm{~s}^{-1}$ in the lowest $190 \mathrm{~m}$ AGL.

In the introduction we discussed that a null hypothesis of $C_{\text {eff }}$ profiles derived by MOST will fail to capture features of real profiles such as jets, variable shear, and temperature inversions, as often is present within valley cities such as Phoenix. We found that NWP with vertical refinement provides 
instances of improvement in representation of $C_{\text {eff below } 190 \mathrm{~m} \text { AGL. Though }}$ some simulation skill was improved with modification of meteorological model resolutions for $1 \mathrm{~km}$ over $3 \mathrm{~km}$, and vertically refined $1 \mathrm{~km}$ over standard $1 \mathrm{~km}$, this study provided a very limited sampling (three 20 min periods) of the entire simulation (several days) and more evaluation is recommended. In particular, detailed observations of profiles below $100 \mathrm{~m}$ AGL are key to meteorological model evaluation for this application.

Methods of evaluation established herein may provide means to move forward in assessing profiles for applicability to investigating highway noise pollution. In particular, profiles of sound speed in conjunction with plots of spectra versus range at various heights are useful for interpreting impacts on the spatial plots of total SPL. Examining relative SPL as total sound pressure level with respect to a fixed range location is useful for comparing an ensemble of predicted field results from derived and observed profiles. Improved agreement was seen between vertically refined profiles and observations as opposed to unrefined profiles. However, the RMSE of $\Delta L$ is biased by choice of range of evaluation and reference distance. Far-field acoustic obervations are needed to properly assess the validity of these methods. Locations for microphone placement can be considered through identifying range windows with large disagreement between the different methods for several meteorological cases. The experimental setup, however, may be limited by site-specific restrictions or proximity to background sources.

For this NWP model configuration some specific details of the wind and temperature gradients are reproduced quite poorly, in comparison with OSF09 observations, yet other aspects were quite well reproduced. More 
work needs to be done to assess possible phase errors and effects of localization of phenomena. Further studies are doubtlessly necessary to ascertain what physical processes are either being approximated poorly for this application (model parameterization), what aspects of the observations are just not resolved (influences of terrain resolution, sampling space-time volume, etc), and the added role of urbanization (not included here) on surface meteorology.

The method of producing surface layer profiles, joining near-ground values to the lowest model level, seems to have a strong influence on the sound field. Even though surface values and first model level values cause a gradient to exist, this changes character with increasing resolution, implying that there were unresolved dynamics in the coarser domain. More analysis needs to be performed with detailed flow observations to assess the hypothesis of unresolved dynamics. What we can glean from the current results is that shear is present in both $\mathrm{d} 04$ and $\mathrm{d} 04 \mathrm{R}$, and so the sound model is going to be influenced in both cases. However, the vertically refined results allow for dynamics not present in the coarser simulation, enabling a closer agreement with observations in some instances.

In cases $\mathrm{A}$ and $\mathrm{C}$, the input effective sound speed profile from the initial unrefined 4th domain NWP simulation, though different from the nonrefracting case, is still not as significantly sheared as for the vertically refined simulation. Moreover, although neither refined nor unrefined $C_{\text {eff }}$ applied to acoustic simulations reproduce all details in the observations, where nearground sound levels remain strong for quite some distance due to ducting of sound, they do produce similar results on the sound field intensity. The 
attenuation versus range results in Figure 10 indicate that near-ground predictions using vertical refinement appear to match more closely the meteorological profiles derived from observations (in comparison to profiles derived from the unrefined domain).

In case B, near-ground upward refraction is eventually overcome further away from the source due to stronger elevated downward refracting conditions. In this case, the shear is well captured. However, the method employed to interpolate between the lowest model level value and the near-ground value, along with bias in either term, can cause strong gradients in $C_{\text {eff, }}$ to which the acoustic field appears quite sensitive. The sensitivity and relative contribution of the interpolation method towards the total refracted field, in comparison with the profile features higher above ground level, needs to be explored for various ranges of propagation.

\section{Conclusions}

In summary, our work shows that conditions of morning temperature inversion and low-level jet or wind shear can be simulated by NWP to a certain degree, but that their magnitudes at a given location and time of comparison may disagree with field observations. As observed in case $\mathrm{C}$, the velocity and temperature components within the effective sound speed can counteract each other and make an otherwise poor representation of the medium yield a $C_{\text {eff }}$ profile which produces a sound field not too unlike what might be observed. Some of these effects measured in the field could be due to smaller-scale ground boundary conditions not realized in the $1 \mathrm{~km} \mathrm{x} 1 \mathrm{~km}$ grid used in the WRF model. For instance, details of the flow modification 
due to terrain and land-use and land-cover may not be present, which, if accounted for, may lead to a closer representation of the actual measured profiles. Furthermore, sub-grid influence of the roadway and terrain[45], and traffic produced turbulence[46], in the local meteorology on acoustic propagation was also not explored in our study.

We recommend further work to consider sensitivities in the models, both of the acoustic propagation model to differing levels of sound speed gradient, and also of NWP to various parameterizations of physical processes, such as land surface, urbanization and potential feedback on circulation and dynamics, representation of subgrid turbulence and surface layer profiles. Assessing the skill of these models for a variety of configurations would provide valuable insight into model prediction capability for acoustics applications. Furthermore, sensitivity of meteorological model to physical parameterization, understanding unresolved subgrid aspects and their importance on acoustic field predictions, and possible areas for improvement of meteorological models, are all topics which could be motivated by demands within applications such as acoustics. In particular, nocturnal inversion and morning transition are notoriously difficult to accurately simulate[47, 48]. These are key periods that exhibit downward refraction and wind shear, which are ubiquitously neglected or misrepresented in many acoustic assessments.

\section{Acknowledgments}

This material is based upon work supported by the National Science Foundation (NSF) under EaSM grant EF-1049251 awarded to Arizona State University (ASU), NSF grant DMS 1419593 awarded to ASU, and by the 


\begin{abstract}
Arizona Department of Transportation grant ADOT JPA06014T awarded to ASU. We would also like to thank Christ Dimitroplos for his support of this work along with Mr. Peter Hyde, Prof. J.C.R. Hunt, and the anonymous reviewers for their valuable feedback in preparation of the manuscript. We thank the WRF group at the National Center for Atmospheric Research (NCAR) for providing the WRF code. We also acknowledge the support of the staff at ASU Advanced Computing Center $\left(A^{2} C^{2}\right)$ for maintaining the Saguaro cluster.
\end{abstract}

\title{
References
}

[1] O. Reynolds, On the refraction of sound by the atmosphere., Proc. R. Soc. Lond. 24 (164-170) (1875) 164-167. doi:10.1098/rspl.1875. 0020 .

[2] O. Reynolds, X. Proceedings of learned societies, Philosophical Magazine Series 450 (328) (1875) 62-77. doi:10.1080/14786447508641260.

[3] T. F. W. Embleton, Tutorial on sound propagation outdoors, J. Acoust. Soc. Am. 100 (1996) 31-48. doi:10.1121/1.415879.

[4] E. Salomons, Computational Atmospheric Acoustics, Kluwer Academic Publishers, Dordrecht, Boston, pp. 348, 2001.

[5] N. C. Ovenden, S. R. Shaffer, H. J. S. Fernando, Impact of meteorological conditions on noise propagation from freeway corridors, J. Acoust. Soc. Am. 126 (1) (2009) 25-35. doi:10.1121/1.3129125. 
[6] R. Stull, An introduction to boundary layer meteorology, Kluwer Academic Publishers, Dordrecht, Boston, London, pp. 666, 1988.

[7] D. Heimann, M. Bakermans, J. Defrance, D. Kühner, Vertical sound speed profiles determined from meteorological measurements near the ground, Acta Acust. Acust. 93 (2) (2007) 228-240.

[8] H. J. S. Fernando, Fluid dynamics of urban atmospheres in complex terrain, Annu. Rev. Fluid Mech. 42 (2010) 365-389. doi:10.1146/ annurev-fluid-121108-145459.

[9] C. D. Whiteman, Mountain Meteorology: Fundamentals and Applications, Oxford University Press, New York, Oxford, pp. 355, 2000.

[10] B. Grisogono, L. Kraljevi'c, A. Jerǐcevi'c, The low-level katabatic jet height versus Monin-Obukhov height, Quart. J. Roy. Meteor. Soc. 133 (2007) 2133-2136. doi:10.1002/qj.190.

[11] J. Sun, L. Mahrt, R. M. Banta, Y. L. Pichugina, Turbulence regimes and turbulence intermittency in the stable boundary layer during CASES-99, J. Atmos. Sci. 69 (1) (2012) 338-351. doi:10.1175/JAS-D-11-082.1.

[12] R. M. Banta, L. S. Darby, J. D. Fast, J. O. Pinto, C. D. Whiteman, W. J. Shaw, B. W. Orr, Nocturnal low-level jet in a mountain basin complex. Part I: Evolution and effects on local flows, J. Appl. Meteor. 43 (2004) 1348-1365. doi:10.1175/JAM2142.1.

[13] S.-M. Lee, H. J. Fernando, M. Princevac, D. Zajic, M. Sinesi, J. L. Mcculley, J. Anderson, Transport and diffusion of ozone in the nocturnal 
and morning planetary boundary layer of the Phoenix valley, Environ. Fluid Mech. 3 (4) (2003) 331-362. doi:10.1023/A:1023680216173.

[14] W. J. Shaw, J. C. Doran, R. L. Coulter, Boundary-layer evolution over Phoenix, Arizona and the premature mixing of pollutants in the early morning, Atmos. Environ. 39 (4) (2005) 773-786. doi:10.1016/j. atmosenv.2004.08.055.

[15] A. J. Brazel, H. J. S. Fernando, J. C. R. Hunt, N. Selover, B. C. Hedquist, E. Pardyjak, Evening transition observations in Phoenix, Arizona, J. Appl. Meteor. 44 (2005) 99-112. doi:10.1175/JAM-2180.1.

[16] L. L. Zaremba, J. J. Carroll, Summer wind flow regimes over the Sacramento valley, J. Appl. Meteor. 38 (10) (1999) 1463-1473. doi: 10.1175/1520-0450(1999)038<1463:SWFROT>2.0.CO;2.

[17] J.-W. Bao, S. A. Michelson, P. O. G. Persson, I. V. Djalalova, J. M. Wilczak, Observed and WRF-simulated low-level winds in a high-ozone episode during the central California ozone study, J. Appl. Meteor. Climatol. 47 (9). doi:10.1175/2008JAMC1822.1.

[18] D. K. Wilson, J. M. Noble, M. A. Coleman, Sound propagation in the nocturnal boundary layer, J. Atmos. Sci. 60 (20) (2003) 2473-2486. doi: 10.1175/1520-0469(2003)060<2473:SPITNB>2.0.CO;2.

[19] L. R. Hole, G. Hauge, Simulation of a morning air temperature inversion break-up in complex terrain and the influence on sound propagation on a local scale, Appl. Acoust. 64 (4) (2003) 401-414. doi:10.1016/ S0003-682X(02)00104-4. 
[20] G. Grell, J. Dudhia, D. R. Stauffer, A description of the fifth-generation Penn State/NCAR Mesoscale Model (MM5), NCAR Technical Note NCAR/TN-398+STR, pp. 121 (December 1994).

[21] B. Lihoreau, B. Gauvreau, M. B'erengier, P. Blanc-Benon, I. Calmet, Outdoor sound propagation modeling in realistic environments: Application of coupled parabolic and atmospheric models, J. Acoust. Soc. Am. 120 (110) (2006) 110-119. doi:10.1121/1.2204455.

[22] J. Michalakes, J. Dudhia, D. Gill, T. Henderson, J. Klemp, W. Skamarock, W. Wang, The weather research and forecast model: Software architecture and performance, in: W. Zwieflhofer, G. Mozdzynski (Eds.), Use Of High Performance Computing In Meteorology, Proceedings of the Eleventh ECMWF Workshop, European Centre for Medium-Range Weather Forecasts, World Scientific, Reading, UK, 2004, pp. 156-168, available online at http://wrfmodel.org/wrfadmin/docs/ecmwf 2004.pdf.

[23] W. C. Skamarock, J. B. Klemp, A time-split nonhydrostatic atmospheric model for weather research and forecasting applications, J. Comput. Phys. 227 (7) (2008) 3465-3485. doi:10.1016/j.jcp.2007.01.037.

[24] W. C. Skamarock, J. B. Klemp, J. Dudhia, D. O. Gill, D. M. Barker, M. Duda, X.-Y. Huang, W. Wang, J. G. Powers, A description of the Advanced Research WRF version 3, NCAR Technical Note NCAR/TN475+STR, pp. 113 (June 2008).

[25] A. Mahalov, M. Moustaoui, Vertically nested nonhydrostatic model 
for multiscale resolution of flows in the upper troposphere and lower stratosphere, J. Comput. Phys. 228 (4) (2009) 1294 - 1311. doi: 10.1016/j.jcp.2008.10.030.

[26] M. Moustaoui, A. Mahalov, H. Teitelbaum, V. Grubi si'c, Nonlinear modulation of $\mathrm{O} 3$ and $\mathrm{CO}$ induced by mountain waves in the upper troposphere and lower stratosphere during terrain-induced rotor experiment, J. Geophys. Res.: Atmos. 115 (D19) (2010) $15 . \quad$ doi: 10.1029/2009JD013789.

[27] A. Mahalov, M. Moustaoui, Characterization of atmospheric optical turbulence for laser propagation, Laser Photonics Rev. 4 (1) (2010) 144159. doi:10.1002/lpor.200910002.

[28] A. Mahalov, M. Moustaoui, V. Grubi`si'c, A numerical study of mountain waves in the upper troposphere and lower stratosphere, Atmos. Chem. Phys. 11 (11) (2011) 5123-5139. doi:10.5194/acp-11-5123-2011.

[29] S. Chandler-Wilde, D. Hothersall, Efficient calculation of the Green function for acoustic propagation above a homogeneous impedance plane, J. Sound Vib. 180 (5) (1995) 705 - 724. doi:10.1006/jsvi. 1995.0110.

[30] K. Gilbert, M. White, Application of the parabolic equation to sound propagation in a refracting atmosphere, J. Acoust. Soc. Am. 85 (2) (1989) 630-637. doi:10.1121/1.397587.

[31] M. West, K. Gilbert, R. Sack, A tutorial on the parabolic equation (PE) 
model used for long range sound propagation in the atmosphere, Appl. Acoust. 37 (1) (1992) 31-49. doi:10.1016/0003-682X(92)90009-H.

[32] K. Attenborough, Sound propagation close to the ground, Annu. Rev. Fluid Mech. 34 (2002) 51-82. doi:10.1146/annurev.fluid.34. 081701.143541.

[33] E. M. Salomons, Improved Green's function parabolic equation method for atmospheric sound propagation, J. Acoust. Soc. Am. 104 (1998) 100111. doi:10.1121/1.423260.

[34] M. E. Delany, E. N. Bazley, Acoustical properties of fibrous absorbent materials, Appl. Acoust. 3 (2) (1970) 105-116. doi:10.1016/ 0003-682X(70)90031-9.

[35] W. C. Skamarock, Evaluating high-resolution NWP models using kinetic energy spectra, Mon. Wea. Rev. 132 (12). doi:10.1175/MWR2830.1.

[36] NCEP, NCEP FNL National Center for Environmental Prediction (NCEP) Final (FNL) operational model global tropospheric analyses, continuing from July 1999, National Center for Atmospheric Research, Research Data Archive, ds083.2, http://rda.ucar.edu.

[37] S.-Y. Hong, J. Dudhia, S.-H. Chen, A revised approach to ice microphysical processes for the bulk parameterization of clouds and precipitation, Mon. Wea. Rev. 132 (1) (2004) 103-120. doi:10.1175/ 1520-0493(2004)132<0103:ARATIM>2.0.CO;2.

[38] E. J. Mlawer, S. J. Taubman, P. D. Brown, M. J. Iacono, S. A. Clough, 
Radiative transfer for inhomogeneous atmospheres: RRTM, a validated 
correlated-k model for the longwave, J. Geophys. Res. 102 (D14) (1997) 16663-16682. doi:10.1029/97JD00237.

[39] J. Dudhia, Numerical study of convection observed during the winter monsoon experiment using a mesoscale two-dimensional model, J. Atmos. Sci. 46 (20). doi:10.1175/1520-0469(1989)046<3077:NSOCOD> 2.0.CO;2.

[40] J. S. Kain, The Kain-Fritsch convective parameterization: An update, J. Appl. Meteor. 43 (1) (2004) 170-181. doi:10.1175/1520-0450(2004) 043<0170:TKCPAU>2.0.CO;2.

[41] L. Wicker, W. C. Skamarock, Time splitting methods for elastic models using forward time schemes, Mon. Wea. Rev. 130 (8) (2002) 2088-2097. doi:10.1175/1520-0493(2002)130<2088:TSMFEM>2.0.CO;2.

[42] J. B. Klemp, W. C. Skamarock, J. Dudhia, Conservative split-explicit time integration methods for the compressible nonhydrostatic equations, Mon. Wea. Rev. 135 (8) (2007) 2897-2913. doi:10.1175/MWR3440.1.

[43] S.-Y. Hong, Y. Noh, J. Dudhia, A new vertical diffusion package with an explicit treatment of entrainment processes, Mon. Wea. Rev. 134 (9) (2006) 2318-2341. doi:10.1175/MWR3199.1.

[44] C. J. Willmott, S. G. Ackleson, R. E. Davis, J. J. Feddema, K. M. Klink, D. R. Legates, J. O'Donnell, C. M. Rowe, Statistics for the evaluation and comparison of models, J. Geophys. Res.: Oceans 90 (C5) (1985) 8995-9005. doi:10.1029/JC090iC05p08995. 
[45] S. Di Sabatino, E. Solazzo, P. Paradisi, R. Britter, A simple model for spatially-averaged wind profiles within and above an urban canopy, Boundary-Layer Meteor. 127 (1) (2008) 131-151. doi:10.1007/ s10546-007-9250-1.

[46] R. Eskridge, J. Hunt, Highway modeling, part 1: Prediction of velocity and turbulence fields in the wake of vehicles, J. Appl. Meteor. 18 (1979) 387-400. doi:10.1175/1520-0450(1979)018<0387:

HMPIPO>2.0.CO;2.

[47] H. Fernando, J. Weil, Whither the stable boundary layer - a shift in the research agenda, Bull. Amer. Meteor. Soc. 91 (11) (2010) 1475-1484. doi:10.1175/2010BAMS2770.1.

[48] A. Holtslag, G. Svensson, P. Baas, S. Basu, B. Beare, A. Beljaars, F. Bosveld, J. Cuxart, J. Lindvall, G. Steeneveld, et al., Stable atmospheric boundary layers and diurnal cycles: challenges for weather and climate models, Bull. Amer. Meteor. Soc. 94 (11) (2013) 1691-1706. doi:10.1175/bamS-d-11-00187.1. 


\section{Figure 1}
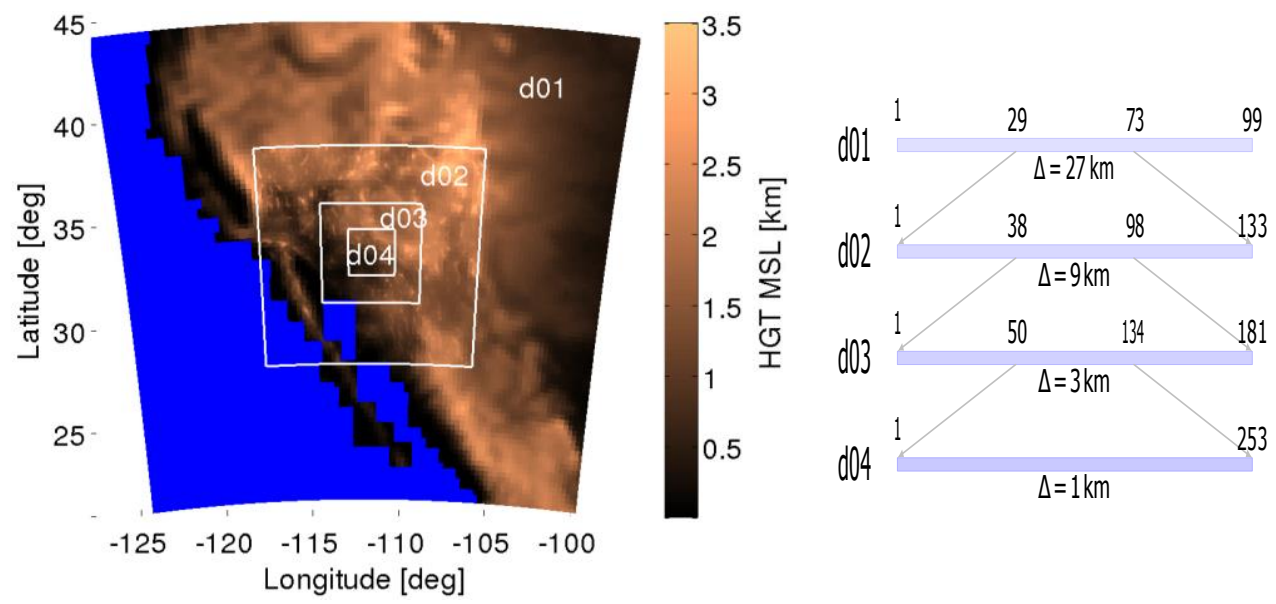

(a)

(b)

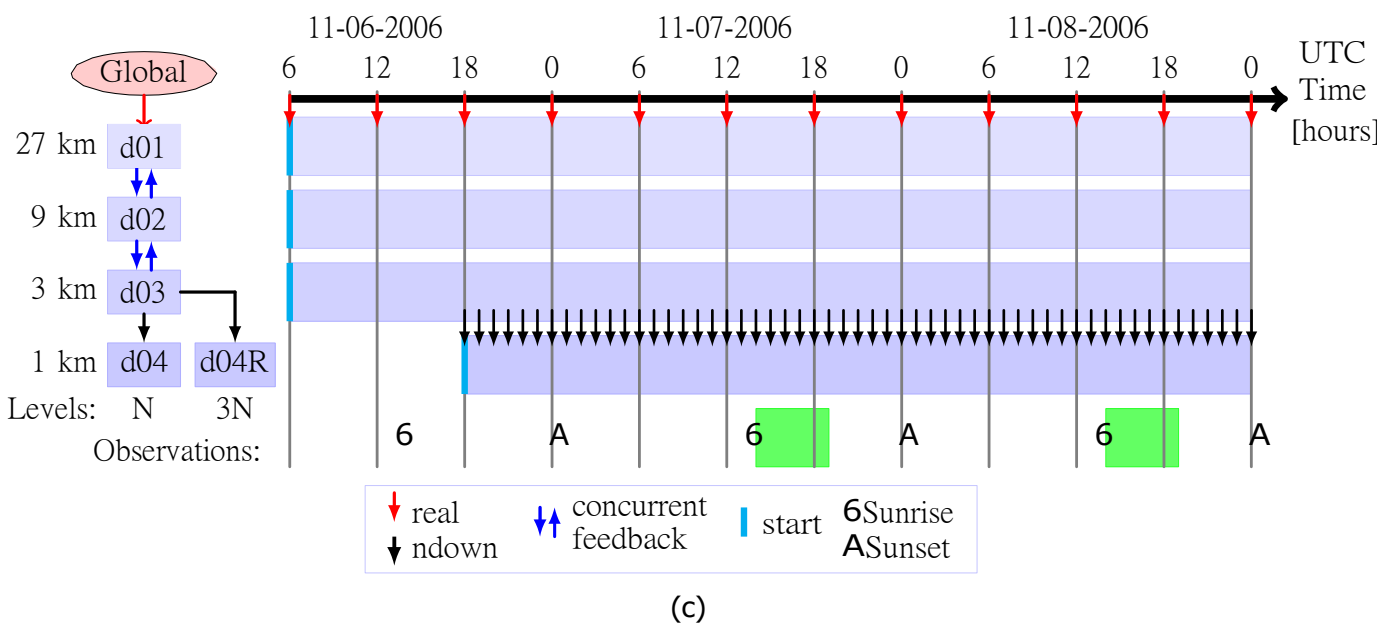




\section{Figure 2}

\section{Site 3D d03 d04 $\triangle$ d04R}

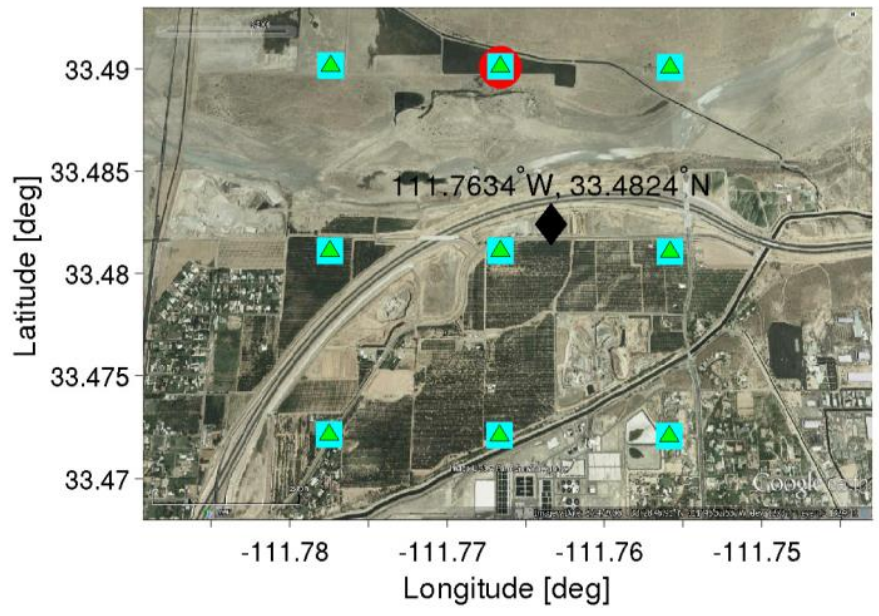


Figefre 3
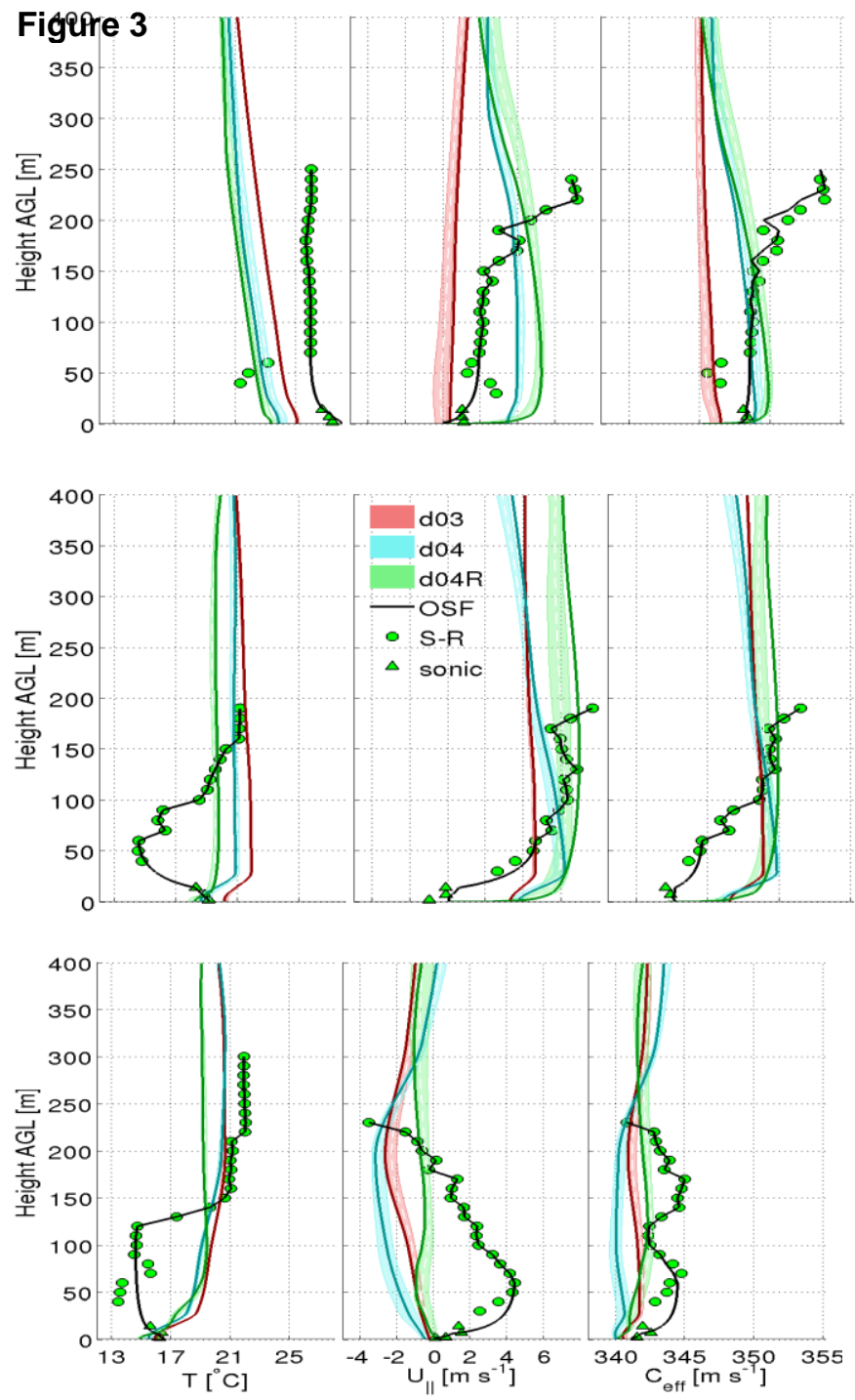


\section{Figure 4}

$$
\mathrm{L}_{\mathrm{A}, \mathrm{f}_{\mathrm{n}}}[\mathrm{dBA}]
$$

\begin{tabular}{lllllllllllllll}
$<37$ & 40 & 43 & 46 & 49 & 52 & 55 & 58 & 61 & 64 & 67 & 70 & 73 & 76 & 79 \\
\hline
\end{tabular}
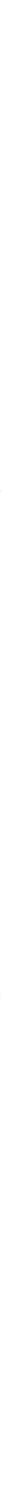
Figure 5

$\mathrm{L}_{\mathrm{A}, \mathrm{f}_{\mathrm{n}}}[\mathrm{dBA}]$

\begin{tabular}{lllllllllllllll}
$<37$ & 40 & 43 & 46 & 49 & 52 & 55 & 58 & 61 & 64 & 67 & 70 & 73 & 76 & 79 \\
\hline
\end{tabular}
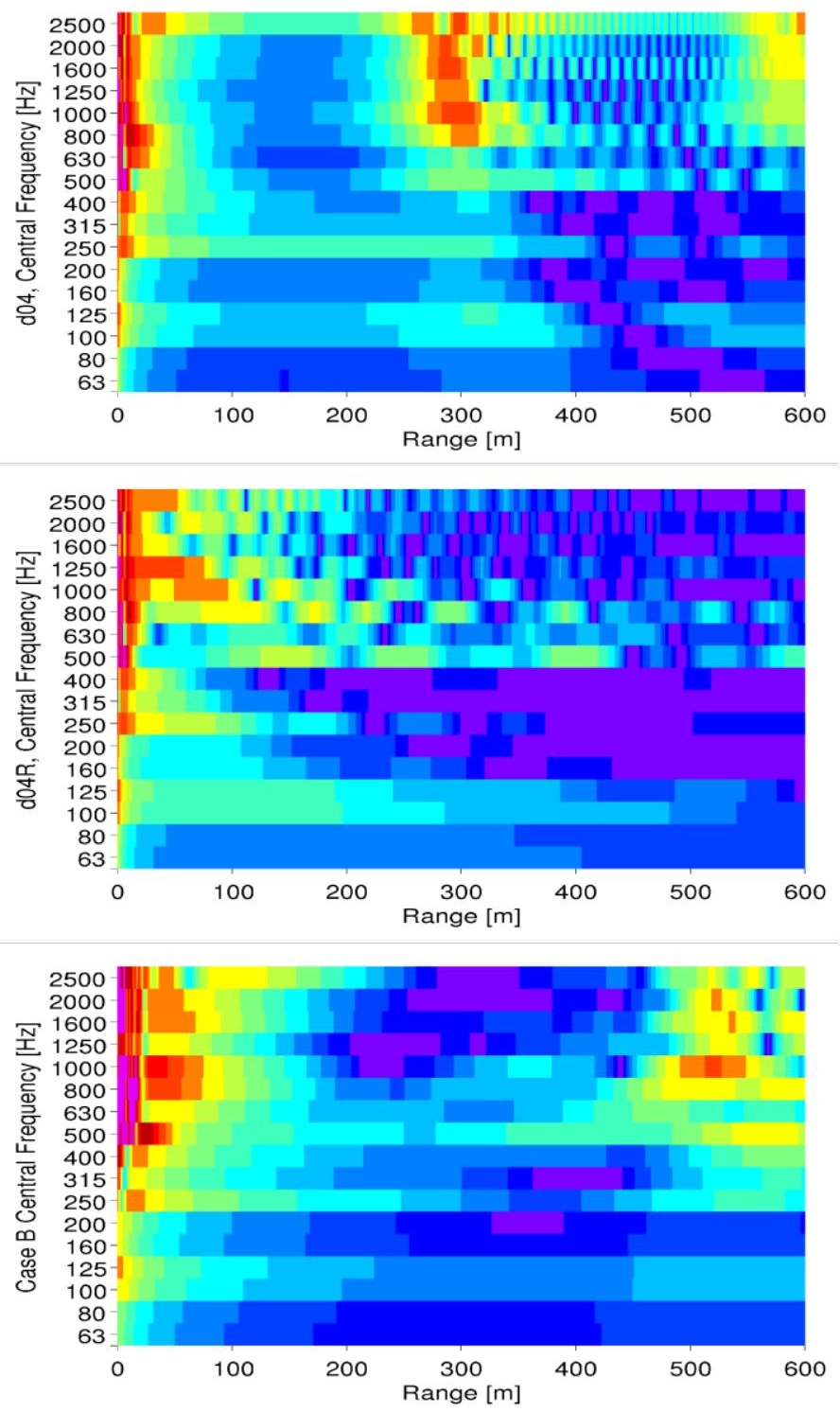
Figure 6

$\mathrm{L}_{\mathrm{A}, \mathrm{f}_{\mathrm{n}}}[\mathrm{dBA}]$

\begin{tabular}{lllllllllllllll}
$<37$ & 40 & 43 & 46 & 49 & 52 & 55 & 58 & 61 & 64 & 67 & 70 & 73 & 76 & 79 \\
\hline
\end{tabular}
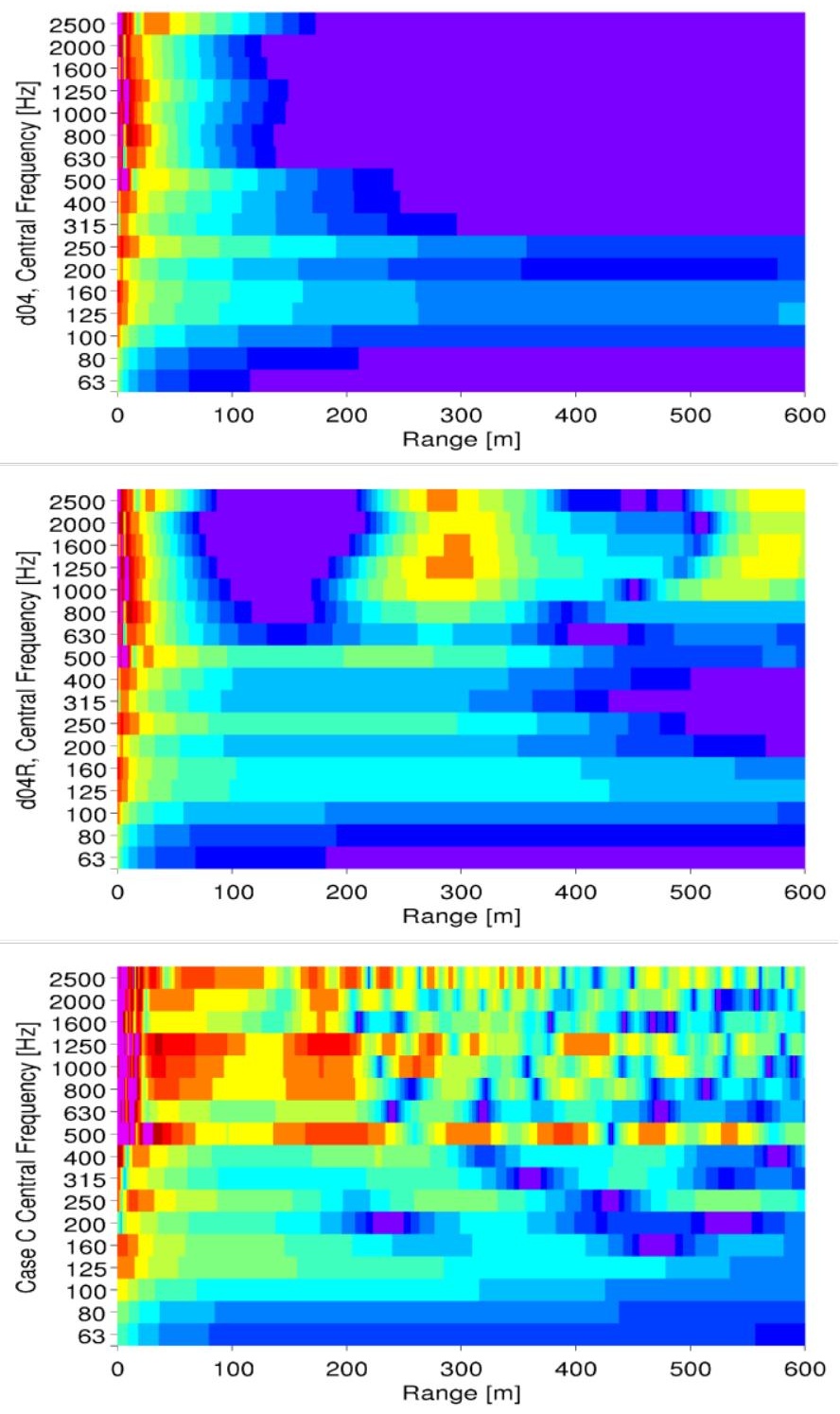


\begin{tabular}{llllllllllll}
$<49$ & 52 & 55 & 58 & 61 & 64 & 67 & 70 & 73 & 76 & 79 & 82 \\
\hline
\end{tabular}
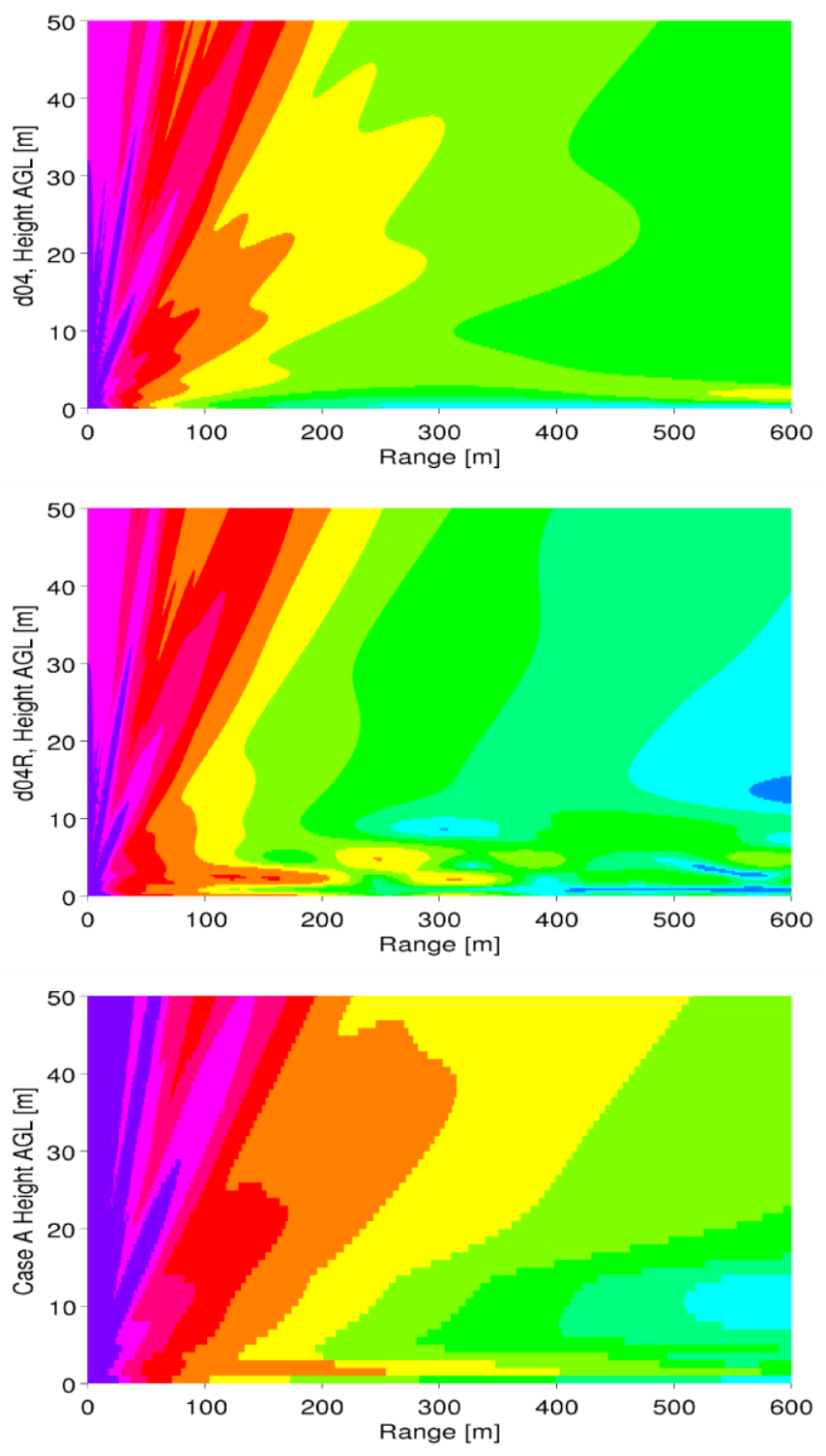


\begin{tabular}{llllllllllll}
$<49$ & 52 & 55 & 58 & 61 & 64 & 67 & 70 & 73 & 76 & 79 & 82 \\
\hline
\end{tabular}
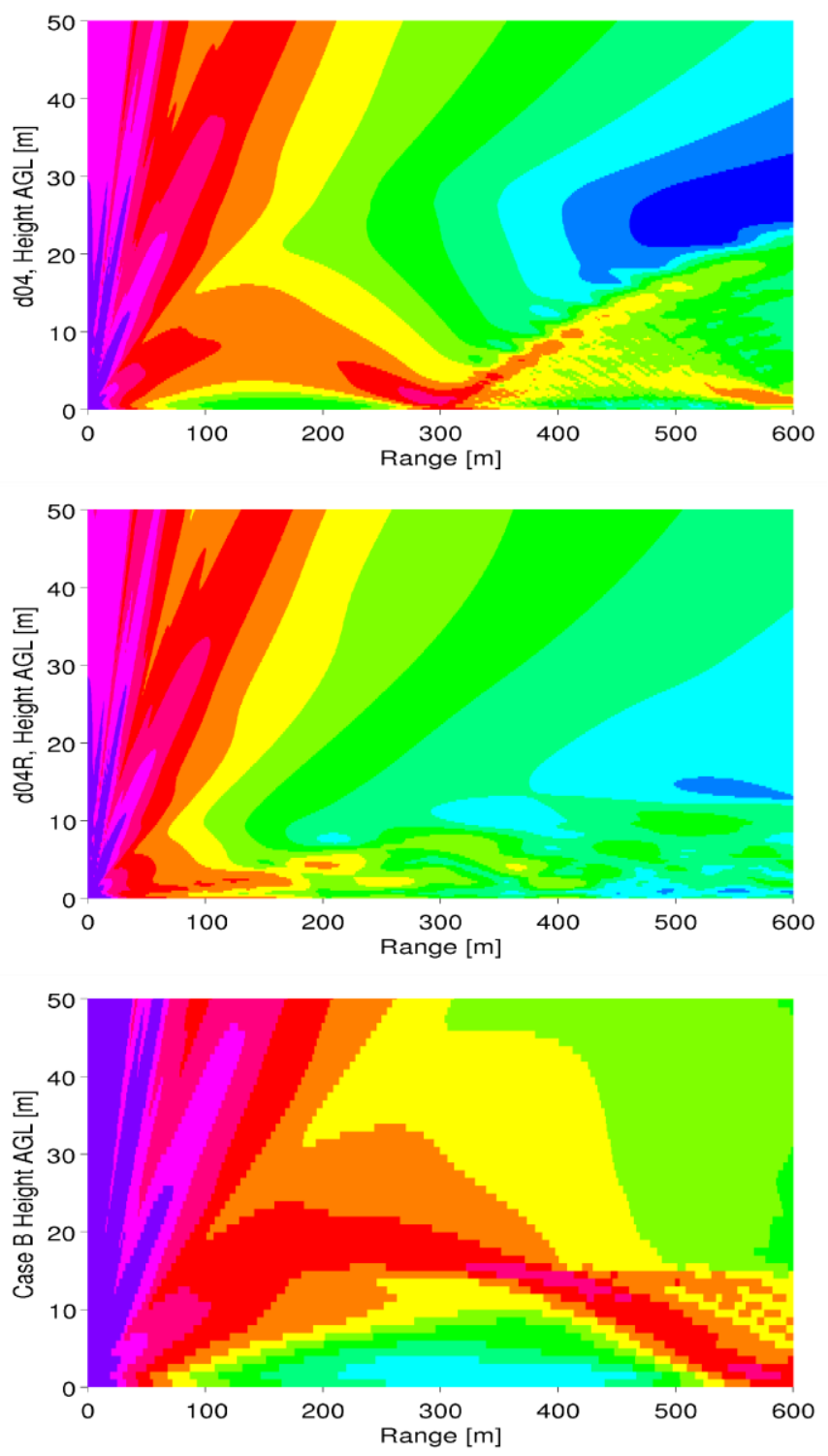


\begin{tabular}{llllllllllll}
$<49$ & 52 & 55 & 58 & 61 & 64 & 67 & 70 & 73 & 76 & 79 & 82 \\
\hline
\end{tabular}
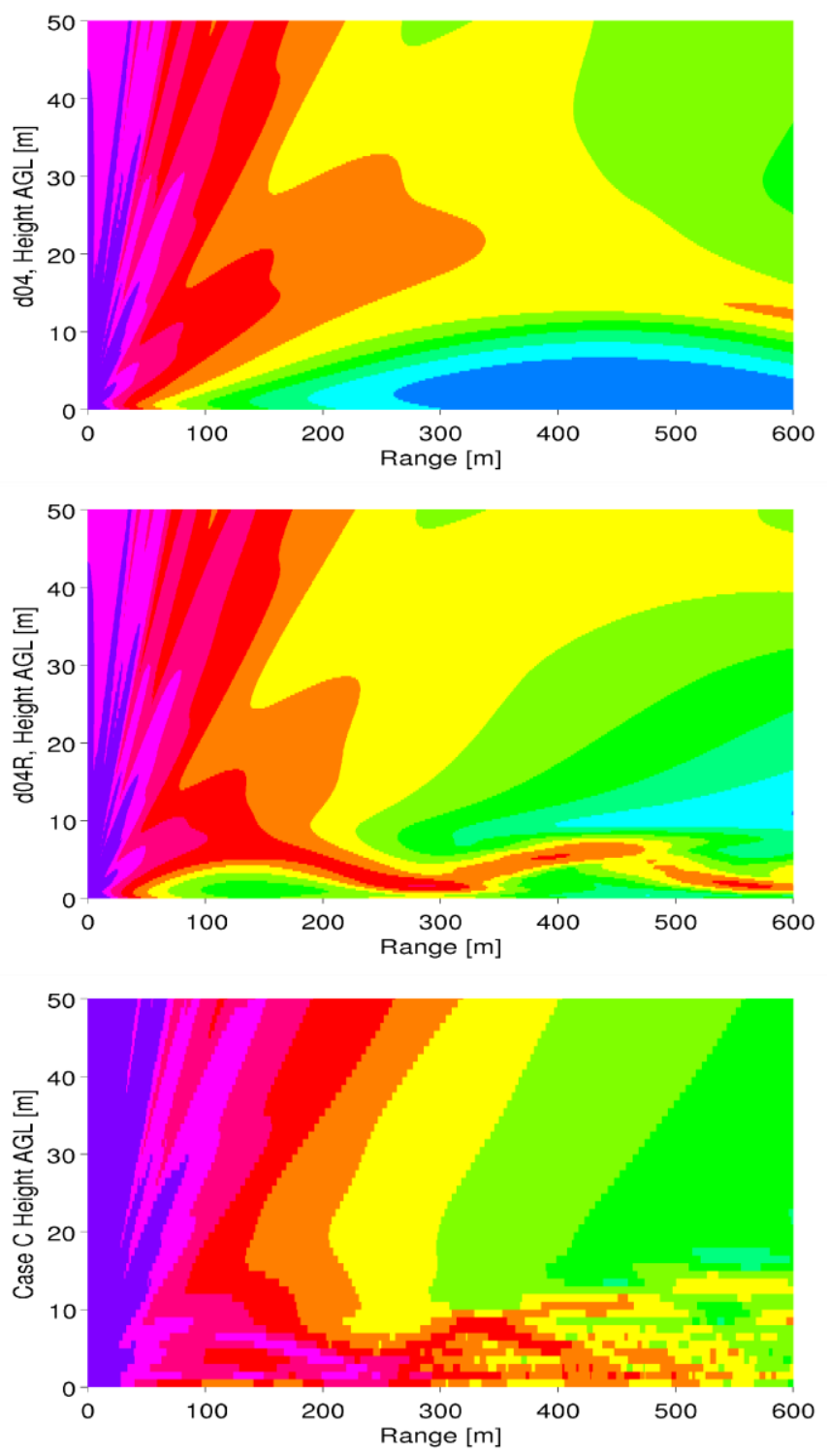

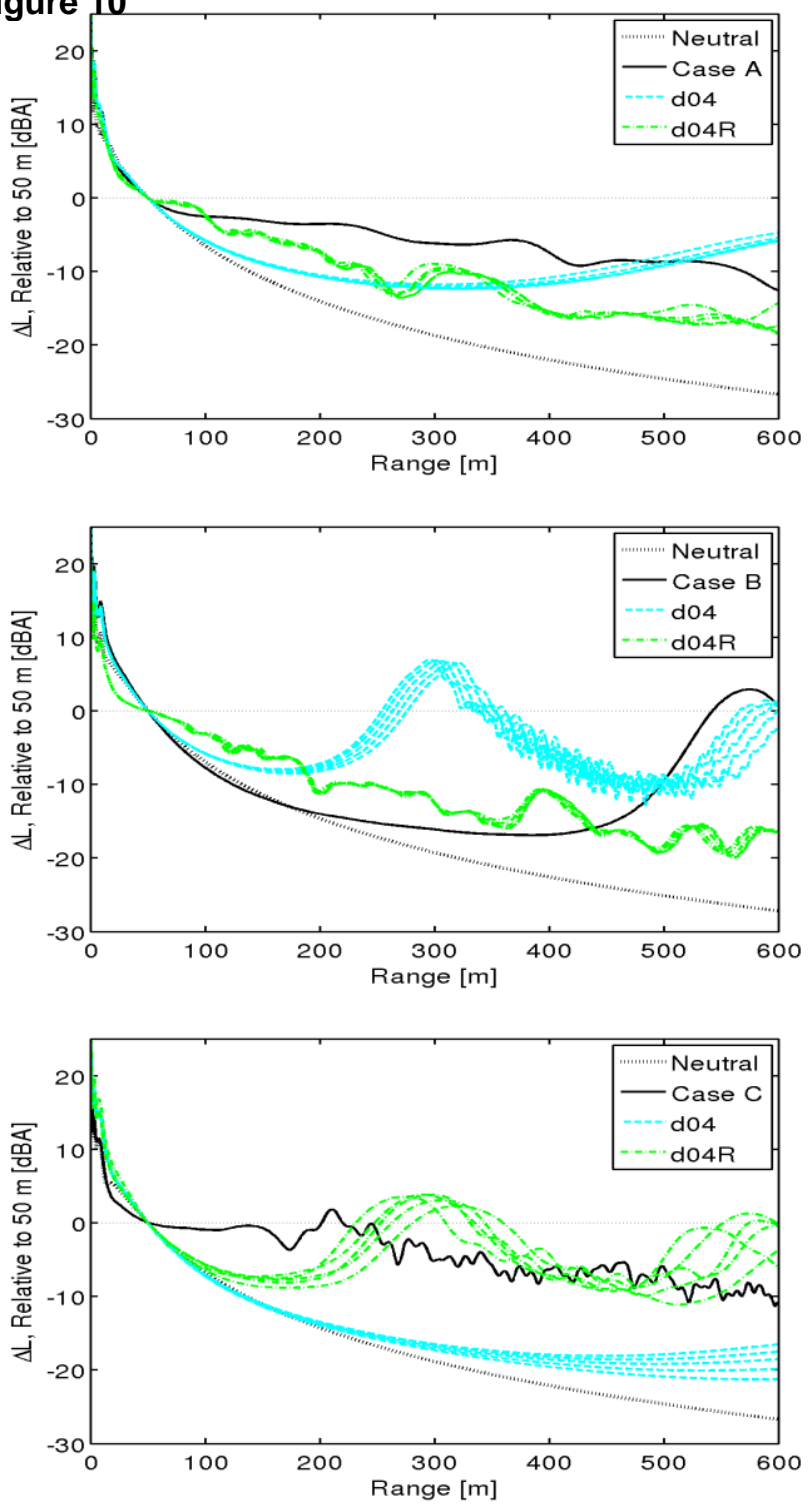
LaTeX Source Files
Click here to download LaTeX Source Files: Shaffer_etal_WRF_PE_submit.tex

LaTeX Source Files
Click here to download LaTeX Source Files: Shaffer_etal_WRF_PE_submit.tex Click here to download LaTeX Source Files: Shaffer_etal_WRF_PE_submittex

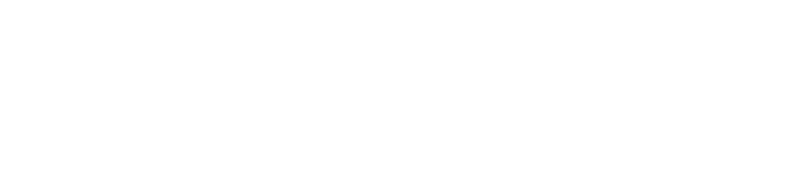
(1) (1) (1) (1) (1) (1) (1) . . .

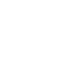

